\title{
ARTICLE
}

\section{A model of TH17-associated ileal hyperplasia that requires both IL-17A and IFN $\gamma$ to generate self-tolerance and prevent} colitis

Jonathan C. Jeschke ${ }^{1}$, Christopher G. Mayne ${ }^{1,7}$, Jennifer Ziegelbauer ${ }^{1}$, Christopher L. DeCiantis ${ }^{1}$, Selina Singh ${ }^{1}$, Suresh N. Kumar ${ }^{2}$, Mariko Suchi ${ }^{2}$, Yoichiro Iwakura ${ }^{3,4}$, William R. Drobyski ${ }^{5}$, Nita H Salzman ${ }^{6}$ and Calvin B. Williams ${ }^{1}$

Homeostasis in the ileum, which is commonly disrupted in patients with Crohn's disease, involves ongoing immune responses. To study how homeostatic processes of the ileum impact CD4 ${ }^{+} \mathrm{T}$ cell responses, we used TCR transgenic tools to breed mice that spontaneously produced $\mathrm{CD} 4^{+} \mathrm{T}$ cells reactive to an antigen expressed in the ileum. At an early age, the ilea of these mice exhibit crypt hyperplasia and accumulate increased numbers of $T_{H} 17$ cells bearing non-transgenic clonotypes. Half of these mice subsequently developed colitis linked to broad mucosal infiltration by $T_{H} 17$ and $T_{H} 1$ cells expressing non-transgenic clonotypes, chronic wasting disease and loss of ileal crypt hyperplasia. By contrast, adult mice with normal growth continued to exhibit $T_{H} 17-$ associated ileal crypt hyperplasia and additionally accumulated ileal-reactive Treg cells. Both IL-17A and IFN $\gamma$ were protective, as their deficiency precluded ileal-reactive Treg accumulation and exacerbated colitic disease. IL-23R blockade prevented progression to colitis, whereas nTreg cell transfers prevented colitic disease, ileal crypt hyperplasia and ileal-reactive Treg accumulation. Thus, our studies identify an IL-17A and IFNY-dependent homeostatic process that mobilizes ileal-reactive Treg cells and is disrupted by IL-23.

Mucosal Immunology (2018) 11:1127-1137; https://doi.org/10.1038/s41385-018-0023-6

\section{INTRODUCTION}

Inflammatory bowel disease (IBD), including Crohn's disease and ulcerative colitis, is a collection of human disorders characterized by a breakdown in mucosal tolerance. ${ }^{1}$ Biologic therapies targeting TNFa and other immunosuppressive interventions can induce remission. However, some patients remain refractory, relapses are common, and many patients demonstrate a loss of efficacy with time. ${ }^{2,3}$ A more complete understanding of IBD immunopathogenesis is needed to develop new therapies that reduce inflammation while simultaneously restoring durable mucosal tolerance.

In Crohn's disease, both $\mathrm{T}_{H} 1$ and $\mathrm{T}_{H} 17$ cells are components of the inflammatory lesions and reducing their development with an IL-12p40 neutralizing antibody shows therapeutic efficacy. ${ }^{4}$ By contrast, neutralizing their canonical cytokine products IFNy or IL$17 \mathrm{~A}$ has limited benefit, ${ }^{5}$ with anti-IL-17A treatment increasing adverse events. ${ }^{6}$ These clinical trial results were not predicted by mouse colitis models as IFN $\gamma$ is generally necessary for pathology ${ }^{7}$ and IL-17A demonstrates both protective and pathogenic roles in the same model of colitis. ${ }^{8,9}$ Anti-inflammatory regulatory $T$ (Treg) cells also accumulate in IBD lesions ${ }^{10}$ demonstrating that part of the $\mathrm{CD}^{+} \mathrm{T}$ cell accumulation is an attempt to limit disease. It is likely that we underestimate the non-pathogenic contributions of
$T_{H} 1$ and $T_{H} 17$ cells, given that many assumptions are based on highly penetrant mouse models with excessive effector $T_{H}$ cell activity.

Immunologic function and homeostatic activity vary across different regions of the gastrointestinal tract. ${ }^{11}$ In contrast to the colon, where dense mucus physically limits microbial access to the epithelium, ${ }^{12}$ the small intestine needs to absorb a broader array of nutrients and the mucus is more permeable. ${ }^{13}$ Paneth cells and their antimicrobial products help limit commensal microbes from penetrating to the epithelial layer in the ileum. ${ }^{14,15}$ This activity is important, as Crohn's disease risk variants for Nod2, Atg16/1, Kcnn4, and Xbp 1 all disrupt anti-microbial production and Paneth cell function. ${ }^{16}$ The ileum also normally hosts $\mathrm{CD} 4^{+} \mathrm{T}$ cells, and $\mathrm{T}_{\mathrm{H}} 17$ cells in particular can induce epithelial anti-microbial production via their secreted cytokine products, including IL$17 \mathrm{~A} .{ }^{17}$ Further limiting mucus penetration, commensal microbes of the small intestine are more extensively coated by $\lg A$ than their colonic counterparts. ${ }^{18}$ This $\lg \mathrm{A}$ maintains tolerance to commensal microbes and in part requires both resident Treg and $T_{H} 17$ cells. ${ }^{19-22}$ Thus, the ileum demonstrates homeostatic $\mathrm{CD} 4{ }^{+} \mathrm{T}$ cell activity that is important for establishing and maintaining tolerance to the commensal microbiota. Understanding these beneficial immune responses is key for developing

\footnotetext{
${ }^{1}$ Department of Pediatrics, Section of Rheumatology, Medical College of Wisconsin, Milwaukee, WI 53226, USA; ${ }^{2}$ Department of Pathology, Division of Pediatric Pathology, Medical College of Wisconsin, Milwaukee, WI 53226, USA; ${ }^{3}$ Research Institute for Biomedical Sciences, Tokyo University of Science, Chiba 278-0022, Japan; ${ }^{4}$ Core Research for Evolutionary Science and Technology, Japan Science and Technology Agency, Saitama 332-0012, Japan; ${ }^{5}$ Department of Medicine, Bone Marrow Transplant Program, Medical College of Wisconsin, Milwaukee, WI 53226, USA and ${ }^{6}$ Department of Pediatrics, Section of Gastroenterology, Medical College of Wisconsin, Milwaukee, WI 53226, USA Correspondence: Calvin B. Williams (cwilliam@mcw.edu)

${ }^{7}$ Present address: Department of Biology, Viterbo University, La Crosse, WI 54601, USA
}

Received: 21 June 2017 Revised: 3 March 2018 Accepted: 9 March 2018

Published online: 4 May 2018 
IBD therapies that do not interfere with the long-term restoration of tolerance.

We sought to study homeostatic adaptive immune responses in the ileum to better understand the immunopathogenesis of Crohn's disease, which most commonly manifests at this site. Unfortunately, most mouse models of enterocolitis do not show ileal inflammation and those available pose challenges for the study of the non-pathogenic activity of $\mathrm{CD} 4{ }^{+} \mathrm{T}$ cells. To circumvent these limitations, we developed a mouse line expressing a model antigen in the ileum and bred it to an antigen-specific CD4 ${ }^{+} \mathrm{T}$ cell receptor transgenic line. This yielded an incompletely penetrant model of colitis and identified a non-pathogenic $T_{H} 17$-associated ileal process that required both IL-17A and IFNy for tolerance of the ileal model antigen.

\section{RESULTS}

To study immune responses in the ileum, we generated a transgenic mouse system that combined ileal expression of a model antigen with antigen-specific TCR transgenic mice. We used the well-characterized antigen hen egg lysozyme (HEL) fused to the transmembrane region of $\mathrm{L}^{\mathrm{d}}$ (mHEL) and expressed this construct under control of the human defensin 5 (HD5) promoter (HD5-mHEL; Fig. S1A). Transgenic HD5-mHEL mice expressed the mHEL mRNA product only among cells at ileal crypt bases and not the colon or duodenum (Fig. S1B-D). To study if HD5-mHEL expression would draw HEL-reactive $\mathrm{CD} 4^{+} \mathrm{T}$ cells to the ileum, we sorted $\mathrm{CD} 4{ }^{+} \mathrm{CD} \mathrm{a}^{-} \mathrm{Foxp}^{-}{ }^{-}\left(\mathrm{T}_{\text {conv }}\right.$ ) cells from $\mathrm{Rag}^{-/-}$mice carrying the HEL(46-61)-reactive $3 A 9$ transgenic TCR and transferred $1 \times$ $10^{6} \mathrm{CD}^{+} 3 \mathrm{~A} 9^{+} \mathrm{T}$ cells into HD5-mHEL Rag $^{-/-}$mice and $R a g 1^{-/-}$ controls. After seven days, transferred $\mathrm{CD} 4^{+} 3 \mathrm{~A} 9^{+} \mathrm{T}_{\text {conv }}$ cells were found in higher abundance in ilea of HD5-mHEL $R a g 1^{-1-}$ recipients than $\operatorname{Rag}^{-/-}$controls and were also more abundant than $\mathrm{CD}^{+}{ }^{+} \mathrm{T}_{\text {conv }}$ cells in ilea of untreated WT B6.AKR controls. In $\sim 50 \%$ of $\mathrm{HD} 5-\mathrm{mHEL} \mathrm{Rag}^{-1-}$ recipients we recovered more $\mathrm{CD} 4^{+} 3 \mathrm{~A} 9^{+} \mathrm{T}$ cells from the ileum than were provided in the original transfer dose (Fig. S1E). Though colons from HD5-mHEL ${ }^{+\prime}$ ${ }^{-}$Rag $^{-1-}$ recipients contained more $\mathrm{CD} 4^{+} 3 \mathrm{~A} 9^{+} \mathrm{T}$ cells than the colons of $\mathrm{Rag}^{-/-}$controls, this accumulation was less than the normal abundance of $\mathrm{CD}^{+}{ }^{+} \mathrm{T}_{\text {conv }}$ cells in untreated WT colons and $\sim 100$-fold less than the original transfer dose (Fig. S1E). Together, these results indicate that the HD5-mHEL transgene exhibits expression that is limited to the base of ileal crypts and is sufficient to promote ileal-specific accumulation of mHEL-reactive $\mathrm{CD} 4{ }^{+} \mathrm{T}_{\text {conv }}$ cells.

Early spontaneous $T_{H} 17$-associated ileal hyperplasia gives way to an incompletely penetrant $T_{H} 17$ and $T_{H} 1$-associated colitis

To create mice with spontaneous ileal $\mathrm{CD} 4{ }^{+} \mathrm{T}$ cell self-reactivity, we crossed $3 \mathrm{~A}^{+/-}$mice to $\mathrm{HD} 5-\mathrm{mHEL}^{+/-}$mice and studied them at 4 discrete time points (Fig. 1a). At weaning, all genotypes had a similar weight, however by the juvenile age (50 \pm 7 days old), $3 \mathrm{~A} 9^{+/-} \mathrm{HD} 5-\mathrm{mHEL}^{+/-}$progeny ('Bigenic' genotype) weighed less than age-matched littermate controls (Fig. 1b). Similarly, circulating $C D 4^{+} T_{E M}$ cells of Bigenic mice went from being less frequent at weaning to almost four times more frequent in juveniles, with the magnitude of this increase highest for the smallest mice (Fig. 1c). The ileal mucosa of juvenile Bigenic mice showed crypt hyperplasia with an average increase in crypt depth of $35 \%$ (Fig. 1d), while no difference in Paneth cell abundance was appreciated. Both the ileal lamina propria and mesenteric lymph nodes $(\mathrm{mLN})$ showed increased $T_{H} 17$ cell accumulation (Fig. 1e). Serum cytokines provided further indication of a $T_{H} 17$-associated process as IL-6, CCL20, IL-22, IL-17A, IL17F, and TNFa were increased (Fig. 1f). Though $\mathrm{T}_{\mathrm{H}} 17$ cells can facilitate neutrophil recruitment, ${ }^{23}$ neutrophil staining in juvenile Bigenic ilea was reduced relative to $3 A 9$ tissue and similar to WT controls (Fig. 1g). These findings revealed the presence of a $T_{H} 17$-associated crypt hyperplasia in the ilea of juvenile Bigenic mice that was linked to restricted growth without a concomitant increase in neutrophil accumulation or obvious loss of Paneth cells.

Next, we studied the evolution of these distinct mucosal features by aging Bigenic mice to 150 days while closely monitoring their weight. We observed an incompletely penetrant and variably expressed weight loss phenotype that frequently exhibited a relapsing and remitting course (Fig. 2a). To identify mice with this weight loss or any other growth abnormality ('symptomatic'), we determined when an individual mouse was 2 standard deviations smaller and had poor growth or experienced 2 standard deviations more weight loss than $\sim 120$ WT littermate controls. In contrast to the few control mice that met these criteria, most symptomatic Bigenic (Bigenic ${ }^{5}$ ) mice continued to lose weight following diagnosis (Fig. 2b). By 100 days ("early adult" age), approximately $50 \%$ of Bigenic mice were symptomatic whereas only $3 \%$ of control mice met these criteria (Fig. 2c; left). Incidence of weight symptomatology was highest during the juvenile period and declined with age (Fig. 2c; right). Thus, half of Bigenic ${ }^{S}$ mice diagnosed by 100 days first met criteria within 25 days from weaning. These observations demonstrate the incomplete penetrance of a chronic wasting disease in Bigenic mice and reveal its declining incidence after the juvenile period.

The declining incidence of symptomatology with age led us to determine if the mucosal features present in juvenile mice spontaneously resolved in non-symptomatic Bigenic (Bigenic ${ }^{N S}$ ) mice. Paneth cell abundance in aged Bigenic cohorts was grossly similar to controls (data not shown). Interestingly, ileal crypt depth in adult Bigenic ${ }^{N S}$ mice was $42 \%$ greater than age-matched WT controls, indicating that ileal crypt hyperplasia was maintained despite this outcome (Fig. $2 \mathrm{~d}$ ). $\mathrm{T}_{\mathrm{H}} 17$ cell accumulation also remained higher than controls for both the ileal and colonic lamina propria and for the $\mathrm{mLN}$ of adult Bigenic ${ }^{N S}$ mice (Fig. $2 \mathrm{e}-\mathrm{g}$ ). In marked contrast, adult Bigenic ${ }^{S}$ mice had ileal crypt depths similar to control mice (Fig. 2d) and their colonic tissues showed histopathologic features consistent with colitis (Fig. 2h). In further contrast to Bigenic ${ }^{N S}$ mice, the ileal and colonic lamina propria of adult Bigenic ${ }^{S}$ mice accumulated more $T_{H} 17$ cells along with $T_{H} 1$ and Treg cells (Fig. 2e-g). Concordant with a diagnosis-associated increase in $T_{H} 1$ cells, adult Bigenic ${ }^{S}$ mice showed elevated levels of IFNY in the serum (Table S1). Thus, adult Bigenic ${ }^{S}$ mice developed a broader colitic disease state, marked by loss of ileal hyperplasia and a more pronounced mucosal accumulation of CD4 ${ }^{+} \mathrm{T}$ cells. By contrast, adult Bigenic ${ }^{N S}$ mice retained the abnormal features of juvenile mice despite becoming less likely to manifest symptomatology with age, indicating that the mechanism underlying $\mathrm{T}_{\mathrm{H}}$ 17-associated ileal hyperplasia was insufficient to precipitate disease.

Ileal-reactive Treg cells associate with a failure to develop colitic disease

One strength of our model is the capacity to study the developmental fate of both ileal-reactive $3 \mathrm{~A} 9^{+} \mathrm{CD} 4^{+} \mathrm{T}$ cells and the polyclonal $3 \mathrm{~A}^{-} \mathrm{CD} 4^{+} \mathrm{T}$ cell population. Frequency and number of $3 \mathrm{~A}^{+}$clones were decreased among the $\mathrm{CD} 4^{+} \mathrm{T}$ cell population in Bigenic mice relative to $3 A 9$ mice, consistent with negative selection in the thymus (Fig. S2A-B \& Table S2). To determine if the $\mathrm{CD} 4^{+} \mathrm{T}$ cells from juvenile Bigenic ilea were enriched in the $3 \mathrm{~A} 9^{+}$ clonotype, we compared the frequency of $3 \mathrm{~A}^{+}$clones between ileal and colonic $\mathrm{CD} 4^{+} \mathrm{T}$ cell populations from individual mice. Within the Bigenic cohort, the $3 \mathrm{~A}^{+}$clonotype was more frequent among ileal $\mathrm{CD}^{+} \mathrm{T}$ cells. This stands in contrast to control $3 \mathrm{~A} 9$ mice lacking the $\mathrm{mHEL}$ transgene, where $3 \mathrm{~A}^{+}$clones were more frequent among colonic $\mathrm{CD} 4^{+} \mathrm{T}$ cells (Fig. 3a). Next we determined the activation status of $3 A 9^{-}$and $3 A 9^{+} T_{\text {conv }}$ clones in the $\mathrm{mLN}$. Within individual juvenile Bigenic mice, $3 A 9^{-} T_{\text {conv }}$ cells were $2 \times$ more likely to have an effector/memory phenotype than $3 \mathrm{~A} 9^{+} \mathrm{T}_{\text {conv }}$ cells (Fig. 3b). $3 \mathrm{~A} 9^{+}$clones were less frequent among 
a

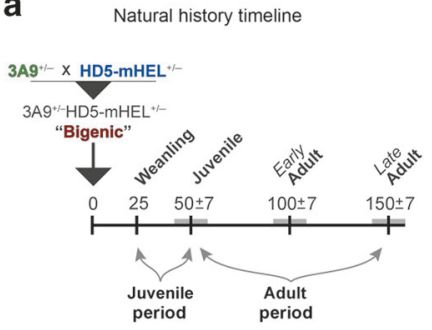

b

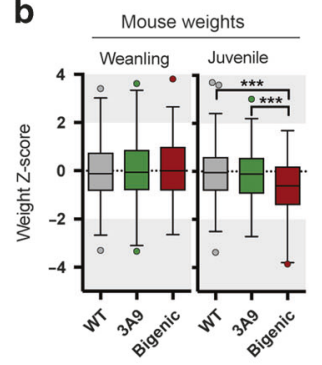

C

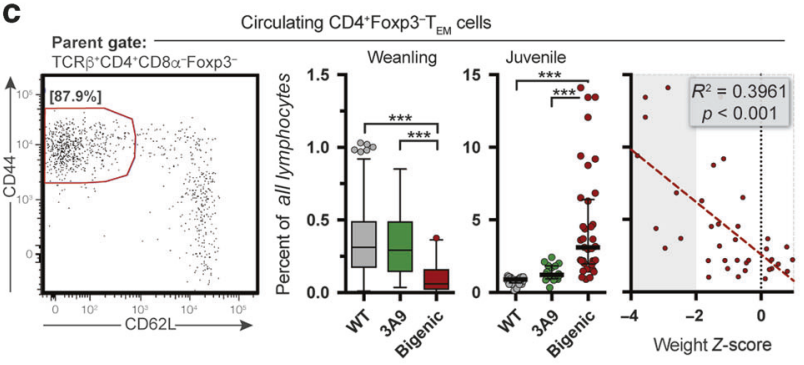

d

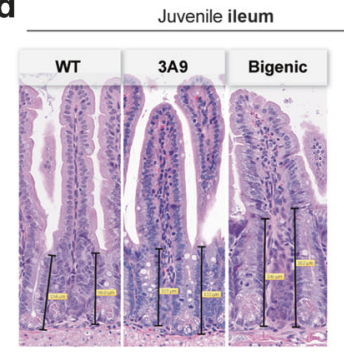

e

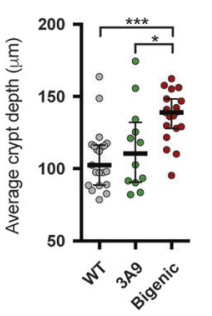

e Parent gate: Juvenile ileum
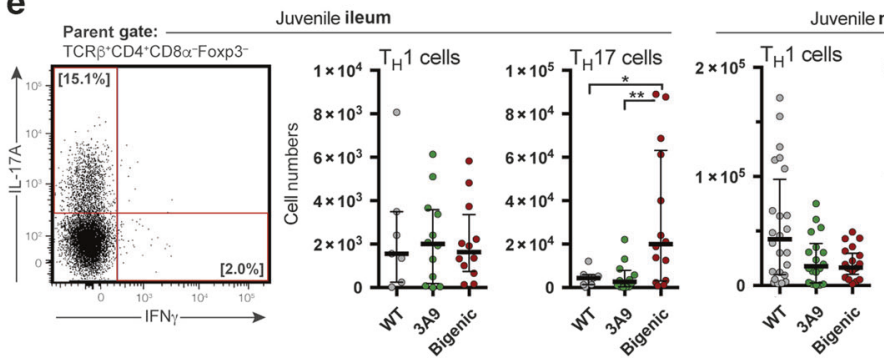

Juvenile $\mathrm{mLN}$

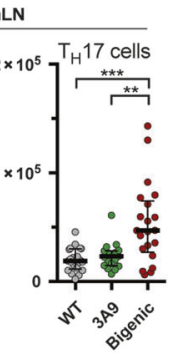

f

Juvenile serum

g
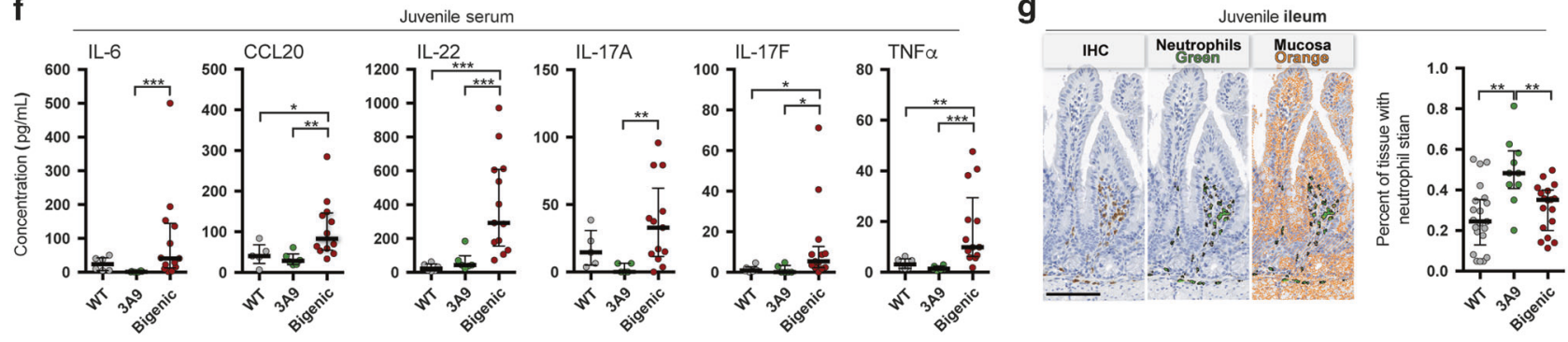

Fig. $1 \mathrm{~T}_{H}$ 17-associated ileal hyperplasia without neutrophil increase in juvenile mice. a Bigenic mouse breeding schematic with ages and ageranges ("Weanling age" $23 \pm 2$ days; "Juvenile age" $50 \pm 7$ days; "Early Adult age" $100 \pm 7$ days; "Late Adult age" $150 \pm 7$ days; "Juvenile agerange" between weanling and juvenile ages) of mice analyzed in our study. $\mathbf{b}$ Mouse weights for WT, 3A9 and Bigenic mice normalized to age and sex (Weight $Z$-score). Weight at weaning (WT $n=491,3 \mathrm{~A} 9 n=155$, Bigenic $n=338$ ) and at juvenile (WT $n=316,3 \mathrm{~A} 9 n=131$, Bigenic $n=$ 147) ages. $c$ Percent of live circulating cells that are $T C R \beta^{+} C D 4^{+} C D 8^{-}$Foxp $3^{-} C D 44^{+} C D 62 L^{-}\left(C D 4^{+} T_{E M}\right)$ for WT, $3 A 9$ and Bigenic mice. Shown at weanling (WT $n=271$, 3A9 $n=36$, Bigenic $n=118$ ) and juvenile (WT $n=28,3 \mathrm{~A} 9 n=18$, Bigenic $n=37$ ) ages. Correlation to weight $Z$-score at time of observation for Juvenile Bigenic cohort shown. FACS plot representative of CD4 ${ }^{+} \mathrm{T}_{\mathrm{EM}}$ as a percent of TCR $\beta^{+} \mathrm{CD} 4^{+} \mathrm{CD} 8^{-}$Foxp3 $3^{-}$cells. $\mathbf{d}$ Average lleal crypt depths for juvenile WT $(n=21), 3 A 9(n=12)$ and Bigenic $(n=19)$ mice. Representative crypts lengths shown for WT (104,

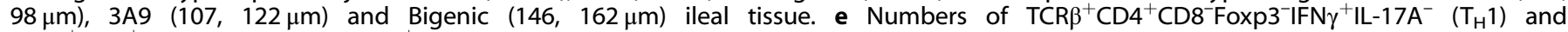
$\mathrm{TCR} \beta^{+} \mathrm{CD} 4^{+} \mathrm{CD}^{-}$Foxp3 ${ }^{-} \mathrm{IFN} \gamma^{-} \mathrm{IL}-17 \mathrm{~A}^{+}\left(\mathrm{T}_{\mathrm{H}} 17\right)$ cells accumulating in juvenile WT, 3A9 and Bigenic mice. Numbers from mLN (WT $n=24,3 \mathrm{~A} 9$ $n=19$, Bigenic $n=21$ ) and ileum (WT $n=7,3 A 9 n=12$, Bigenic $n=14$ ) and representative FACS plot shown from Bigenic ileum. $f$ Serum concentrations of $\mathrm{T}_{\mathrm{H}}$ 17-associated cytokines from juvenile WT $(n=6), 3 \mathrm{~A} 9(n=6)$ and Bigenic $(n=13)$ mice. Cytokines IL-6, CCL20, IL-22, IL17A, IL-17F, and TNF $\alpha$ shown. g Percent of mucosal surface with neutrophil immunohistochemical stain from WT $(n=21), 3 A 9(n=10)$ and Bigenic $(n=18)$ ileal tissue sections. Representative neutrophil IHC section from Bigenic ileum with neutrophil (green) and counter stain (orange) detection indicated. Scale bar reflects $100 \mu \mathrm{m}$

colonic $\mathrm{CD}^{+} \mathrm{T}_{\text {conv }}$ cells from Bigenic $^{\mathrm{S}}$ mice (Figure $\mathrm{S} 2 \mathrm{C}$ ) and Bigenic $\mathrm{CD} 4^{+} \mathrm{T}_{\text {conv }}$ cells transferred colitis to $R a g 1^{-1-}$ mice that lack the HD5-mHEL transgene (Figure S3A-B). Furthermore, 3A9 clonotypes account for most of the $T_{H} 17$ accumulation in the $\mathrm{mLN}$ and ileum (Figure S2D-E). These findings indicate that more $3 \mathrm{~A} 9^{+}$clones are found among $\mathrm{CD} 4^{+} \mathrm{T}$ cells of the ileal mucosa, yet $3 \mathrm{~A} 9^{-}$clonotypes predominate, favor pro-inflammatory lineages and are more likely responsible for colonic disease.

In contrast to $3 \mathrm{~A}^{-} \mathrm{CD} 4^{+} \mathrm{T}$ cells, $60 \%$ of $3 \mathrm{~A}^{+} \mathrm{CD} 4^{+} \mathrm{T}$ cells from juvenile Bigenic $\mathrm{mLNs}$ expressed Foxp3, making them $75 \times$ more likely to be Treg cells than the $3 A 9^{+} C D 4^{+} T$ cells from the $\mathrm{mLN}$ of $3 \mathrm{~A} 9$ mice (Fig. $3 \mathrm{c}$ ). $3 \mathrm{~A} 9^{+}$Treg cells also accumulated in $\mathrm{mLN}$ and ileum of Bigenic mice (Fig. S2F-G, Table S2). Furthermore, $3 \mathrm{~A} 9^{+}$Treg cells increased in the $\mathrm{mLN}$ of adult Bigenic ${ }^{N S}$ mice relative to both juvenile and adult Bigenic ${ }^{S}$ mice (Fig. $3 \mathrm{~d}$ ). These clonotype studies suggest that despite early overproduction of $3 A 9^{-} T_{H} 17$ cells, the in vivo determinants of cell fate in Bigenic ${ }^{N S}$ mice favor tolerogenic lineage-commitment for self-reactive $\mathrm{T}$ cells, in contrast to Bigenic $\mathrm{C}^{\mathrm{S}}$ mice. Expansion of ileal-reactive Treg cells also suggests a mechanism whereby Bigenic mice reduce the incidence of colitic disease with age.

IL-17A and IFNY are required for ileal-reactive Treg accumulation As Bigenic mice age, they either accumulate ileal-reactive Treg cells or develop colitic disease linked to a broad increase in mucosal $\mathrm{T}_{\mathrm{H}} 17$ cells. This led us to examine how IL-17A contributed to ileal-reactive Treg accumulation and the incidence of colitic disease by breeding $1 / 17 a^{-/-}$Bigenic mice. The absence of IL-17A had little effect on the incidence of the wasting disease or on weight loss following diagnosis (Fig. $4 a-b)$. Similar to Bigenic ${ }^{N S}$ mice, ileal crypt hyperplasia remained in $1 / 17 a^{-/-}$Bigenic $^{N S}$ mice, indicating that IL-17A was not necessary for this tissue response (Fig. 4c). As compared to $1117 a^{+/+}$Bigenic $^{S}$ mice, $1 / 17 a^{-/-}$Bigenic $^{S}$ mice manifested colitis yet with greater distension of the lamina 
a

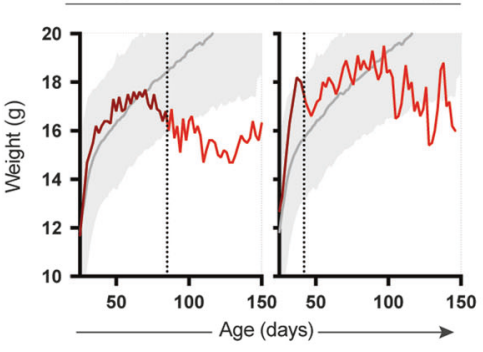

b

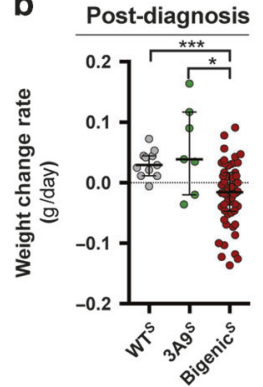

C

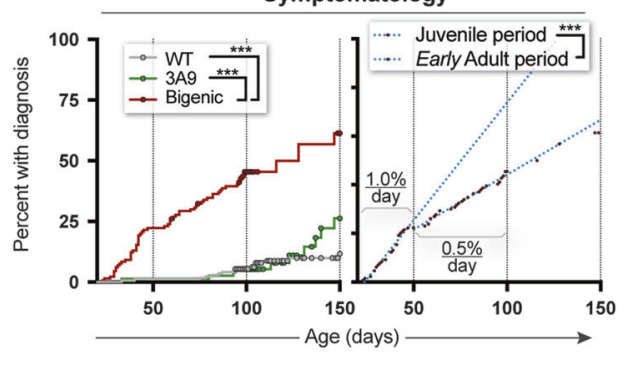

d

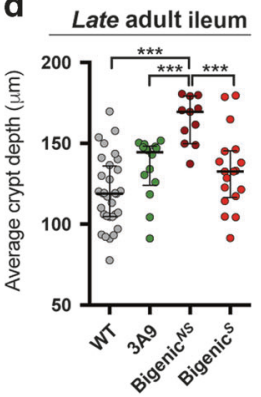

e

Early adult ileal lamina propria

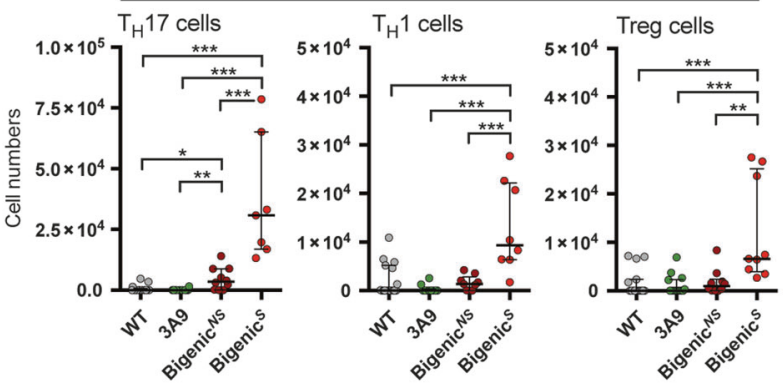

f

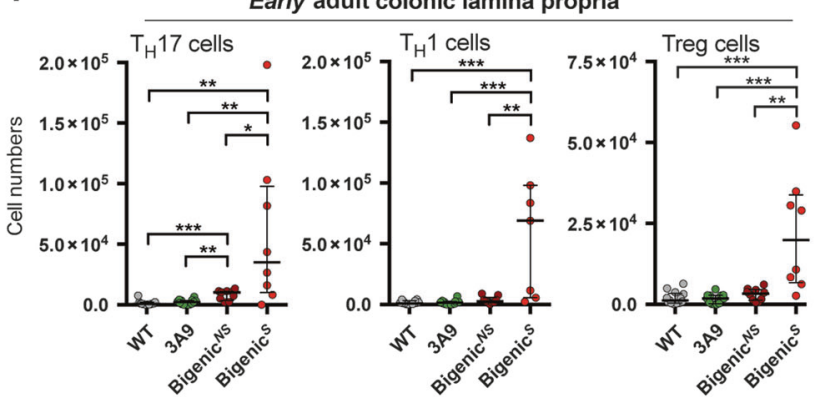

h

$9 \quad$ Early adult mesenteric lymph nodes
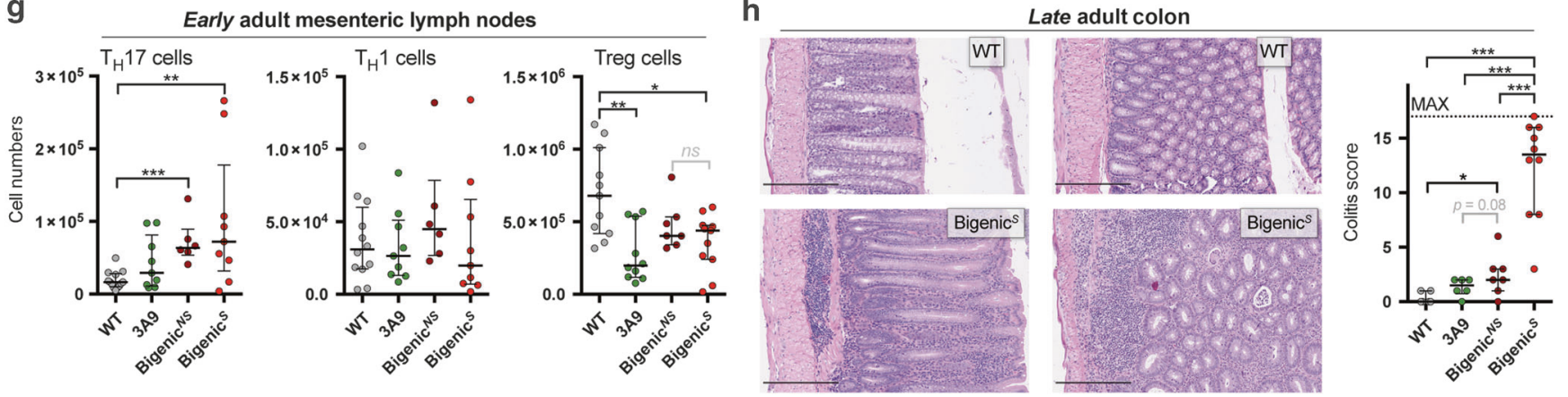

Fig. 2 Colitis-associated wasting disease initiates early and loses ileal hyperplasia. a Representative growth curves for two Bigenic mice exhibiting a weight loss phenotype. Dashed vertical line indicates when the mouse first showed two standard deviations more weight loss than age and sex-matched control mice. $\mathbf{b}$ Weight change rate following initial manifestation of the wasting phenotype for WT (WT $n=11)$, $3 \mathrm{~A} 9\left(3 \mathrm{~A} 9^{S} n=7\right)$ and Bigenic (Bigenic $\left.\mathrm{c}^{5} n=54\right)$ mice reaching early adult age. c Prevalence of a wasting phenotype among WT $(n=166), 3 \mathrm{~A} 9(n$ $=74)$, and Bigenic $(n=111)$ mice (left). Linear regression of prevalence vs. age from either the juvenile period or from the 50 to 100 -day agerange of the Bigenic cohort (slope $=$ incidence). d lleal crypt depths for late Adult WT $(n=32), 3$ A9 $(n=14)$, Bigenic ${ }^{N S}(n=11)$, and Bigenic $(n$ $=17$ ) mouse cohorts. Bigenic ${ }^{S}$ mouse cohort includes mice euthanized before late Adult age $(n=5 ;$ median age $=104$ days). $\mathbf{e}-\mathbf{g}$ Numbers of $\mathrm{T}_{\mathrm{H}} 17, \mathrm{~T}_{\mathrm{H}} 1$ and Treg cells from ileum (e), colon (f), and $\mathrm{mLN}(\mathbf{g})$. WT $(n=15), 3 \mathrm{~A} 9(n=14)$, Bigenic $^{N S}(n=10)$ and Bigenic ${ }^{S}(n=9)$ mice from early Adult age studied given the high specificity for diagnosis relative to control mice and the equivalent penetrance of Bigenic ${ }^{N S}$ and Bigenic ${ }^{S}$ phenotypes. $\mathbf{h}$ Colitis scores from cohort shown in panel (d). Representative WT (top) and Bigenic ${ }^{S}$ (bottom) colonic tissue H\&E sections showing crypt hyperplasia (bottom; left), goblet cell loss (bottom; left), submucosal infiltration (bottom; both) and crypt abscesses (bottom; right). Scale bars reflect $250 \mu \mathrm{m}$

propria by infiltrating cells and more frequent lymphoid aggregates (Fig. 4d, S4A). In parallel, both the ileal and colonic lamina propria in $1 / 17 a^{-1-}$ Bigenic ${ }^{5}$ mice accumulated more $T_{H} 1$ and Treg cells as compared to $1 / 17 a^{+/+}$Bigenic $^{S}$ mice (Fig. 4e, f). Finally, $1 / 17 a^{-/-}$Bigenic $^{N S}$ mice failed to accumulate $3 A 9^{+}$Tregs in the $\mathrm{mLN}$ despite unchanged $3 A^{-} 9^{-}$Treg accumulation (Fig. 4g). These data indicate that IL-17A limits $\mathrm{T}_{\mathrm{H}} 1$ accumulation in the mucosae of Bigenic $^{S}$ mice and is required for ileal-reactive Treg accumulation in Bigenic ${ }^{N S}$ mice, consistent with a protective role.

To better characterize the early regulatory environment of $1 / 17 a^{-/-}$Bigenic mice, we transferred a $1 \times 10^{6}$ cells of a $1: 1$ mixture containing Thy $1.1^{+} 3 \mathrm{~A} 9^{+}$and Thy $1.1^{+} 3 \mathrm{~A}^{-}$(polyclonal) naïve $\mathrm{T}_{\text {conv }}$ cells into newly weaned Thy $1.2^{+} / 117 a^{-/}$Bigenic mice. After seven days, approximately $65-70 \%$ of the recovered Thy $1.1^{+} 3 \mathrm{~A} 9^{-}$ population were activated when recovered from either $1117 a^{-/-}$ or $1117 a^{+/+}$Bigenic mice (Fig. 4h). Activation largely favored a $T_{H} 17$ lineage in both Bigenic strains (Fig. $4 \mathrm{i}) .3 \mathrm{~A} 9^{+} \mathrm{T}_{\text {conv }}$ cells recovered from $1117 a^{+/+}$Bigenic mice remained naïve and the small frequency that expressed activation markers did not produce either IL-17A or IFNy (Fig. $4 \mathrm{~h}, \mathrm{i}$ ). In contrast, $\sim 70 \%$ of $3 \mathrm{~A} 9^{+} \mathrm{T}_{\text {conv }}$ cells recovered from $1 / 17 a^{-1-}$ Bigenic mice were activated and favored the development of a $T_{H} 17$ cell phenotype (Fig. 4h, i). These findings indicate that the regulatory environment of $1117 a^{-/}$ -Bigenic mice fails to prevent the pro-inflammatory development of ileal-reactive naïve $\mathrm{CD} 4^{+} \mathrm{T}$ cells.

The infiltration of $T_{H} 1$ cells in the lamina propria of Bigenic ${ }^{S}$ mice suggested that elimination of the $T_{H} 1$-produced cytokine IFN $\gamma$ might facilitate development of ileal-reactive Treg cells. To test this possibility, we bred Ifng $^{-/-}$Bigenic mice and monitored disease progression. Surprisingly, nearly all (98\%) Ifng ${ }^{-/}$Bigenic mice initiated disease within the juvenile period (Fig. 5a, b) revealing a dominant role for IFNY in preventing morbidity. 
a Juvenile ileal and colonic $3 \mathrm{~A} 9^{+} \mathrm{CD} 4^{+} \mathrm{T}$ cells

\section{b}

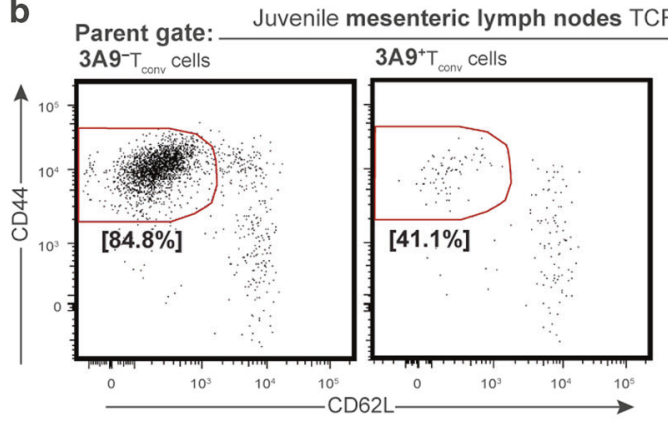

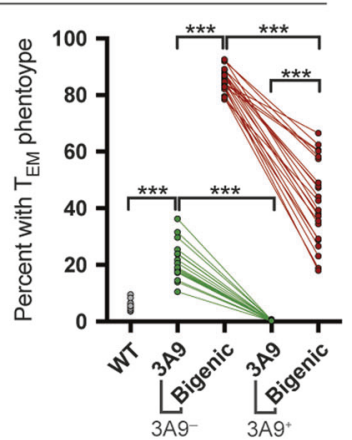

C

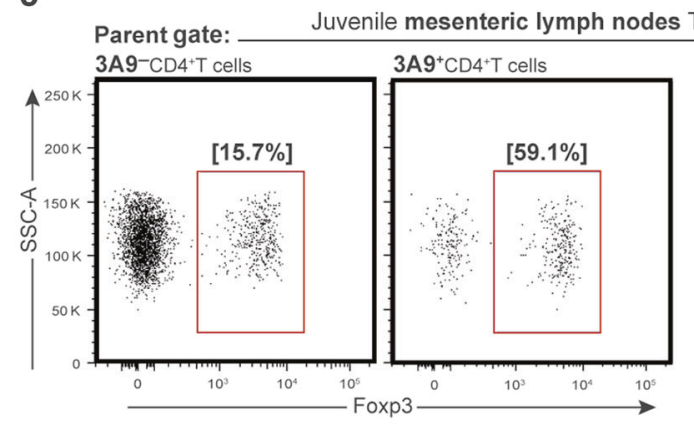

d
Juvenile mesenteric lymph nodes

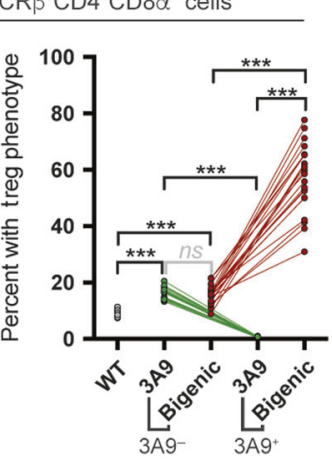
TCR $\beta^{+} \mathrm{CD}^{+} \mathrm{CD} 8 \alpha^{-}$Foxp $3^{+}$cells

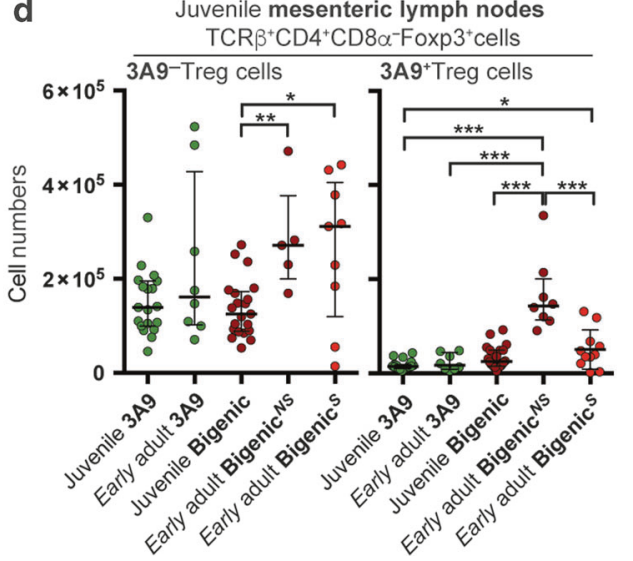

Fig. $3 \mathrm{mLN} 3 \mathrm{~A}^{+}$Treg cells increase with age in Bigenic ${ }^{N S}$ mice. a Ratio of $3 \mathrm{~A} 9$ clonotype abundance among ileal CD4 ${ }^{+} \mathrm{T}$ cells relative to $3 \mathrm{~A} 9$ clonotype abundance among colonic CD4 ${ }^{+}$T cells. Ratio calculated from FACS analysis of paired ileum and colon of juvenile $3 A 9$ ( $\left.n=11\right)$ and Bigenic $(n=14)$ mice. $\mathbf{b} \mathrm{T}_{\mathrm{EM}}$ surface phenotype among $\mathrm{mLN}$ TCR ${ }^{+} \mathrm{CD} 4^{+} \mathrm{CD} 8^{-} \mathrm{Foxp} 3^{-}\left(\mathrm{T}_{\text {conv }}\right)$ cell populations after sub-stratification into $3 \mathrm{~A} 9^{+}$ and $3 \mathrm{~A}^{-}$clonotype groups. Paired $3 \mathrm{~A}^{-}$and $3 \mathrm{~A}^{+}$clonotype groups from same mouse indicated with connecting line and significance for paired samples reflects result of Wilcoxon matched-pairs signed rank test. Juvenile WT $(n=25), 3 A 9(n=19)$ and Bigenic $(n=22)$ mice shown. c Treg $\left(\right.$ Foxp $^{+}$) lineage commitment among $\mathrm{mLN} \mathrm{CD} 4^{+} \mathrm{T}$ cell populations after sub-stratification into $3 \mathrm{~A}^{+}$and $3 \mathrm{~A} 9^{-}$clonotype groups. Analysis and cohort same as detailed for panel (b). d $3 A 9^{-}$Treg (left) and $3 \mathrm{~A}^{+}$Treg (right) cell numbers in mLN of Juvenile (3A9 $n=19$; Bigenic $n=22)$ and early adult (3A9 $n=8$; Bigenic ${ }^{N S} n=8$; Bigenic $\left.^{S} n=11\right)$ mice

Additionally, weight loss was non-remitting, ileal crypts were shorter, colitis scores higher, and the lamina propria from both tissues accumulated more $\mathrm{T}_{\mathrm{H}} 17$ cells in Ifng ${ }^{-1-}$ Bigenic mice than in age-matched Ifng ${ }^{+/+}$Bigenic controls (Fig. 5c-g). Treg cell numbers from the ilea of Ifng $^{-/-}$Bigenic mice were not increased (Fig. 5f) and furthermore, the $\mathrm{mLN}$ from Ifng $^{-/}$Bigenic mice showed reduced accumulation of both $3 \mathrm{~A}^{+}$and $3 \mathrm{~A}^{-}$Treg cells (Fig. 5h). Next, we studied the regulatory environment in newly weaned Ifng ${ }^{-/}$Bigenic mice by applying the co-transfer method used for $1 / 17 a^{-/-}$Bigenic mice. $3 A 9^{+} \mathrm{T}_{\text {conv }}$ cells recovered from $/$ fng $^{-/}$ -Bigenic mice were mostly activated and favored a $T_{H}$ 17-lineage (Fig. $5 \mathrm{i}$, j). Similarly, the recovered $3 \mathrm{~A} \mathrm{9}^{-} \mathrm{T}_{\text {conv }}$ cells were more likely to be activated, and once activated, more consistently expressed IL-17A than when transferred into Ifng ${ }^{+/+}$Bigenic mice (Fig. $5 \mathrm{i}, \mathrm{j}$ ). These findings demonstrate that both IL-17A and IFNY play protective roles in the Bigenic model, given that their absence led to an inability to regulate ileal-reactive naïve $C D 4^{+} \mathrm{T}$ cells prior to the onset of colitic disease.

Accelerated disease initiation in $/$ fng $^{-/-}$Bigenic mice requires IL$17 \mathrm{~A}$ and IL-23

The overproduction of $T_{H} 17$ cells associated with the accelerated disease initiation and progression of $/ \mathrm{fng}^{-/-}$Bigenic mice led us to consider a pathogenic role for IL-17A in this genotype. Consistent with our hypothesis, deficiency of IL-17A in Ifng ${ }^{-/-}$Bigenic mice was protective, as the absence of both cytokines reduced the incidence of wasting disease as compared to Ifng $^{-/-}$Bigenic controls (Fig. 6a). However, after developing symptoms, Ifng ${ }^{-1}$ ${ }^{-} / 117 a^{-/-}$Bigenic $^{S}$ mice and $/$ fng $^{-/-}$Bigenic $^{S}$ showed similar weight loss (Fig. 6b). lleal crypt hyperplasia remained a feature of $1117 a^{-1}$ ${ }^{-}$Ifng ${ }^{-1}$ Bigenic $^{N S}$ mice, demonstrating that neither cytokine was required for this tissue response (Fig. $6 \mathrm{c}$ ). Interestingly, colitis was more severe than in Ifng $^{-1-}$ Bigenic $^{S}$ mice, largely due to increasingly distorted mucosal architecture and a $~ 3$-fold increase in crypt abscesses (Fig. 6d, S4B). These findings indicate that in the $\mathrm{T}_{\mathrm{H}}$ 17-overproducting Ifng $^{-/-}$Bigenic mice, IL-17A promotes disease initiation, yet also limits the severity of the colitis that subsequently develops.

Collectively, our studies of $1117 a^{-/-}$and $1 / 17 a^{-/-}$Ifng ${ }^{-/-}$Bigenic mice implicate both pathogenic and protective mechanisms that are dependent upon IL-17A. Given that IL-23, a constitutive product of ileal dendritic cells, ${ }^{24}$ is known to increase the pathogenic potential of IL-17A-producing lymphocytes, ${ }^{25,26}$ we tested whether IL-23R blockade would prevent disease in Ifng $^{-1}$ -Bigenic mice. We began IL-23R blockade (21A4 treatment) at weaning and maintained this blockade through the juvenile period. 21A4-treatment reduced disease incidence and abrogated the progressive weight loss in the few mice that were diagnosed (Fig. 6e, f). lleal crypts in 21A4-treated Ifng ${ }^{-1-}$ Bigenic mice showed marked hyperplasia and the average crypt lengths were also increased relative to age-matched $/$ fng $^{+++}$Bigenic control mice (Fig. 6g). Importantly, 21A4 treatment also prevented colitis in Ifng ${ }^{-1-}$ Bigenic mice (Fig. 6h). 21A4 treatment had no effect on numbers of $m L N T_{H} 17$ cells (data not shown), yet $m L N$ contained 

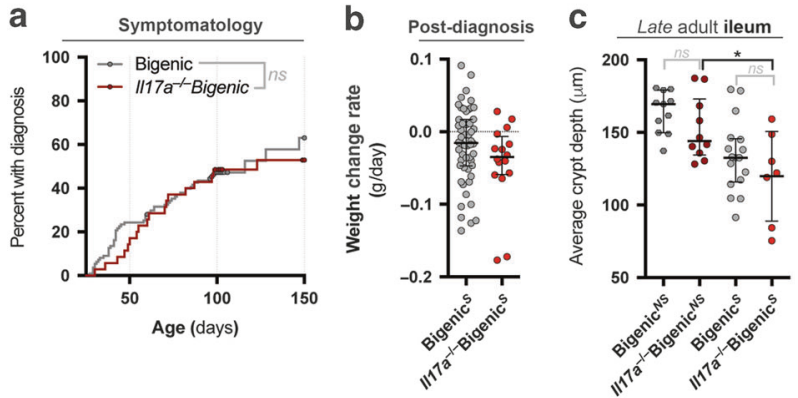

f

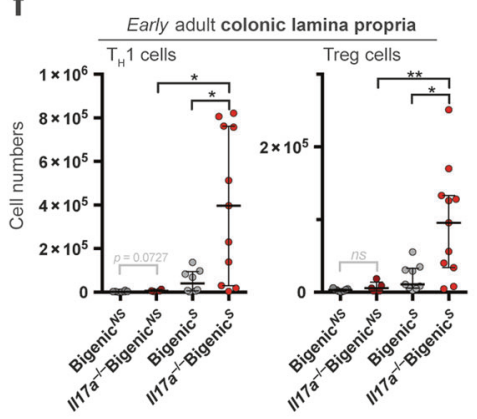

9

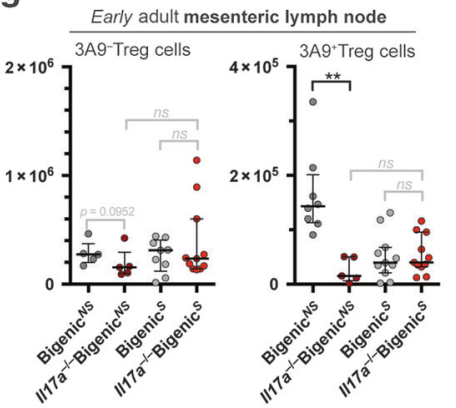

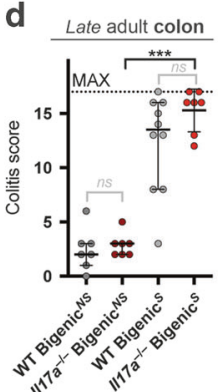

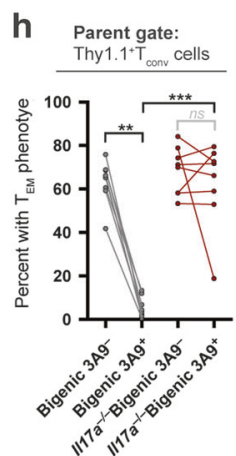

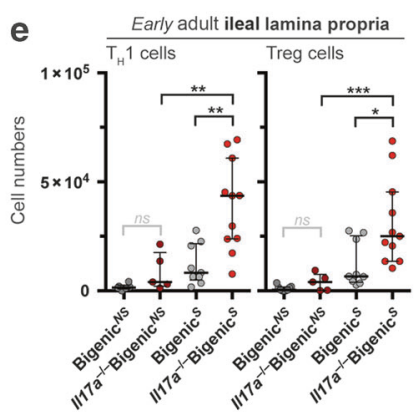

i

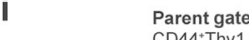
CD44+Thy1.1 $1^{+} T_{\text {con }}$ cells

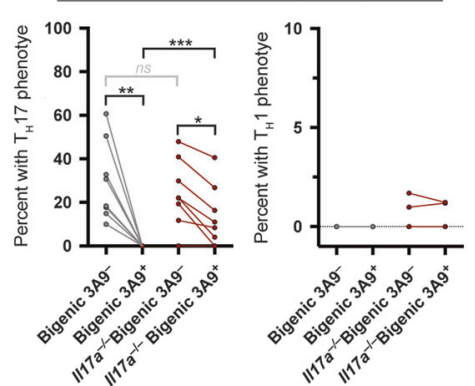

Fig. 4 IL-17A required for tolerance to HEL antigen but not wasting disease. a Prevalence of a wasting phenotype among $/ / 17 a^{-/-}(n=35)$ and $1 / 17 a^{+/+}(n=111)$ Bigenic mice. b Weight change rate following initial manifestation of the wasting phenotype for $/ 17 a^{-/-}(n=54)$ and $/ 117 a^{+/+}$ $(n=18)$ Bigenic mice reaching early adult age. c, d lleal crypt depths (c) and colitis scores (d) for late adult $/ 117 a^{-/-}$Bigenic $^{N S}(n=10), I / 17 a^{-\prime}$ ${ }^{-}$Bigenic $^{S}(n=7)$, Bigenic ${ }^{N S}(n=11)$, and Bigenic ${ }^{S}(n=17)$ mouse cohorts. e, $\mathbf{f}$ Numbers of $\mathrm{T}_{\mathrm{H}} 1$ and Treg cells from ileum (e) and colon (f). Early adult $1117 a^{-1-}$ Bigenic $^{N S}(n=5), 1117 a^{-1-}$ Bigenic $^{S}(n=11)$, Bigenic ${ }^{N S}(n=9)$, and Bigenic ${ }^{S}(n=9)$ mice shown. g 3A9 $9^{+}$Treg and $3 A 9^{-}$Treg cell $^{-1}$ numbers from $\mathrm{mLN}$ of early adult $1117 a^{-1-} \operatorname{Bigenic}^{N S}(n=5), 1117 a^{-1-}$ Bigenic $^{S}(n=11)$, Bigenic ${ }^{N S}(n=8)$, and Bigenic $(n=11)$ mice. $\mathbf{h}, \mathbf{i}$ In vivo polarization of naïve polyclonal Thy $1.1^{+} \mathrm{T}_{\text {conv }}$ cells and $3 \mathrm{~A}^{+}$Thy $1.1^{+} \mathrm{T}_{\text {conv }}$ cells in newly weaned $1117 a^{-/-}(n=8)$ and $/ 17 a^{+/+}(n=8)$ Bigenic mice. Activation (\% $\mathrm{T}_{\mathrm{EM}}$ ) among Thy $1.1^{+} \mathrm{CD} 4^{+} \mathrm{T}_{\text {conv }}$ cell population (h) and lineage commitment (left $\mathrm{T}_{H} 17$; right $\mathrm{T}_{H} 1$ ) among $\mathrm{CD} 44^{+}$Thy $1.1^{+} \mathrm{CD} 4^{+} \mathrm{T}_{\text {conv }}$ cell populations (i) after sub-stratification into $3 \mathrm{~A}^{+}$and $3 \mathrm{~A}^{-}$clonotype groups. Paired $3 \mathrm{~A} 9^{-}$and $3 \mathrm{~A} 9^{+}$clonotype groups from same mouse indicated with connecting line and significance for paired samples reflects result of Wilcoxon matched-pairs signed rank test

more $3{ }^{A} 9^{-}$Treg cells with $3 A^{+} 9^{+}$Treg cells approaching juvenile Ifng ${ }^{+/+}$Bigenic mouse levels (Fig. 6i). These results demonstrate that in the setting of excessive $T_{H} 17$ cell production, IL-23 prevents ileal hyperplasia, promotes acute colitic disease and antagonizes Treg cell accumulation.

nTreg transfer blocks colitic disease, $T_{H} 17$ production and ileal hyperplasia

Neither cytokine deficiency nor IL-23R blockade prevented ileal hyperplasia in Bigenic ${ }^{N S}$ mice, indicating alternative mechanisms were responsible for this early tissue response. $T_{H} 17$ cell development can be triggered by SFB, however fecal SFB showed no relation to genotype or symptomatology (Figure S5A-B). As Bigenic mice produce fewer nTreg cells than WT control mice (Table S2; Fig. 2g, S2B), we hypothesized that reduced nTreg production led to the early $\mathrm{T}_{\mathrm{H}} 17$-associated ileal hyperplasia (Fig. 1c, d) and allowed a dysregulation of microbiota-reactive $3 \mathrm{~A}^{-} \mathrm{CD} 4^{+} \mathrm{T}_{\text {conv }}$ cells in symptomatic mice (Figures $\mathrm{S} 5 \mathrm{C}-\mathrm{D}$ ). To test this possibility, we transferred $5 \times 10^{5}$ polyclonal nTreg cells isolated by cell sorting from Foxp ${ }^{\text {EGFP }}$ B6.AKR mice into newlyweaned Bigenic and Ifng ${ }^{-1-}$ Bigenic mice and studied them through the juvenile period. Supplementation with nTreg cells reduced the incidence of disease in both Bigenic and Ifng $^{-/}$ -Bigenic mice during the juvenile period (Fig. 7a). Additionally, the few nTreg-treated Ifng ${ }^{-/}$Bigenic mice that manifested a weight abnormality gained weight after diagnosis (Fig. 7b). In both genotypes, nTreg transfer reduced ileal hyperplasia, prevented colitis and lowered $\mathrm{T}_{\mathrm{H}} 17$ cell numbers in the $\mathrm{mLN}$ (Fig. 7c-e). This was the first intervention that simultaneously prevented colitic disease and ileal hyperplasia in Bigenic mice. Finally, treating
Bigenic mice with nTregs also reduced $3 \mathrm{~A}^{+}$Treg cells in the $\mathrm{mLN}$ (Fig. 7f) suggesting that the ileal phenotype present in Bigenic ${ }^{N S}$ mice is representative of a compensatory tolerogenic process.

To examine the capacity of a monoclonal population of $3 \mathrm{~A} 9^{+}$Tregs cells to prevent disease, we transferred $5 \times 10^{5}$ in vitro derived $3 \mathrm{~A}^{+}$iTreg cells into newly weaned Ifng $^{-/-}$Bigenic mice. $3 \mathrm{~A} 9^{+} \mathrm{i}$ Treg cell transfer reduced disease incidence (Fig. $7 \mathrm{~g}$ ), though in mice that manifested disease, weight loss was similar to untreated Ifng ${ }^{-/-}$Bigenic mice (Fig. 7h). Since Foxp3 expression is unstable in iTreg cells, ${ }^{27}$ we assessed whether the maintenance of Foxp3 expression in the transferred cells was associated with the outcome. Recovered cells from non-symptomatic mice retained the highest frequency of Foxp ${ }^{+}$cells, and the time to disease onset in symptomatic mice was strongly associated with the maintenance of Foxp3 expression (Fig. 7i). Together, these transfer studies support the notion that the $T_{H} 17$-associated ileal hyperplasia is a feature of a process that limits the impact of partial nTreg deficiency by skewing the differentiation of the selfreactive repertoire toward the Treg compartment.

\section{DISCUSSION}

Our new model of enterocolitis begins with a uniform set of disease determinants in juvenile mice. In adult mice, a spontaneous segregation occurs between the colitis associated with wasting disease and the ileal immunoregulatory state associated with normal growth. Thus, what begins as a continuum of shared susceptibility diverges with age to yield two phenotypically dichotomous outcomes. We conclude that the infiltrative processes active in the ilea of Bigenic ${ }^{N S}$ mice are insufficiently 

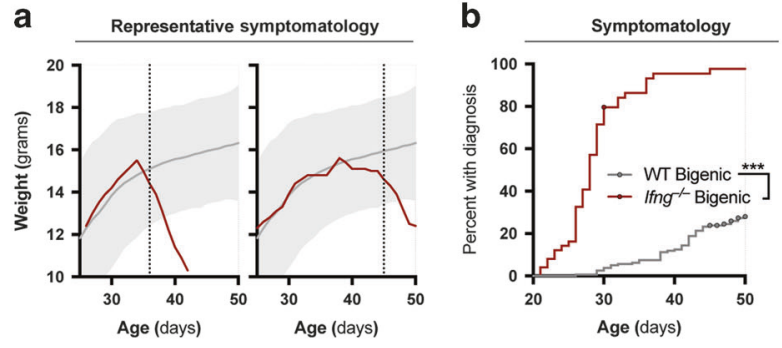
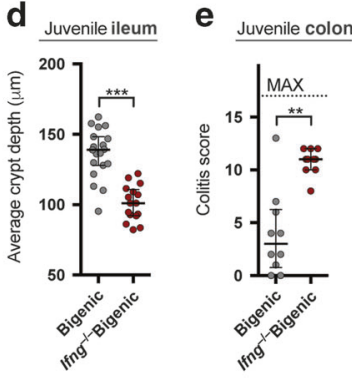

f

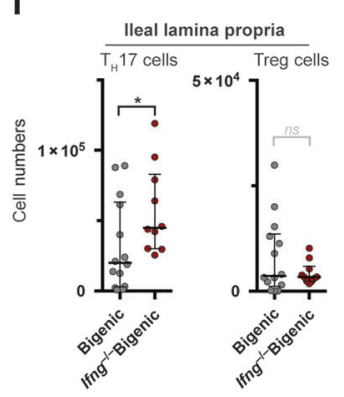

9 Colonic lamina propria

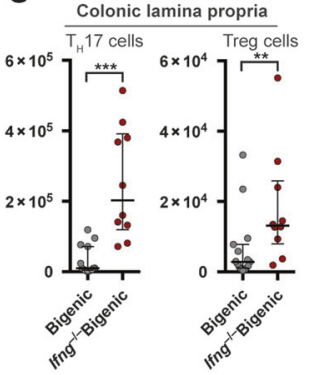

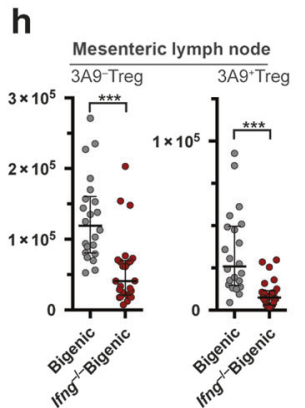
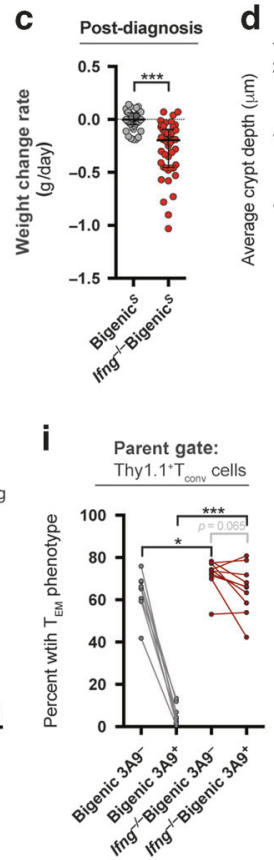

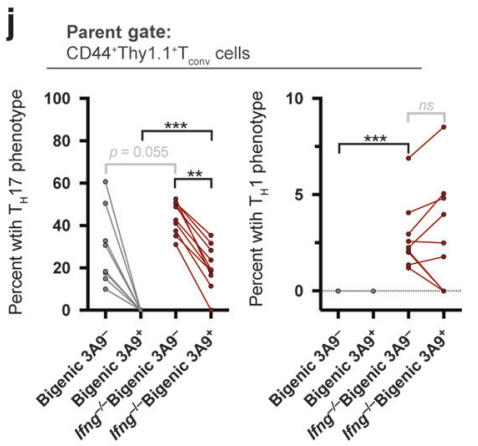

Fig. 5 IFN $\gamma$ required for tolerance to HEL antigen and preventing acute wasting disease. a Representative growth curves for two Ifng ${ }^{-/}$Bigenic mice exhibiting the acute weight loss phenotype. Dashed vertical line indicates when mouse first showed two standard deviations more weight loss than age and sex-matched control mice. b Prevalence of a wasting phenotype among Ifng ${ }^{-/-}(n=49)$ and Ifng ${ }^{+/+}(n=159)$ Bigenic mice during the juvenile period. c Weight change rate during the juvenile period following initial manifestation of the wasting phenotype for Ifng $^{-/-}(n=46)$ and Ifng ${ }^{+/+}(n=41)$ Bigenic mice. d, $\mathbf{e}^{1}$ Ileal crypt depths (d) and colitis scores (e) for juvenile Ifng ${ }^{-/-}(n=16)$ and lfng ${ }^{+/+}(n=19)$ Bigenic cohorts. $\mathbf{f}, \mathbf{g}^{1}$ Numbers of $\mathrm{T}_{\mathrm{H}} 17$ and Treg cells from ileum (f) and colon $(\mathbf{g})$. Juvenile Ifng ${ }^{-/-}(n=10)$ and Ifng ${ }^{+/+}(n=14)$ Bigenic mice shown. $\mathbf{h}^{\mathbf{1}} 3 \mathrm{~A}^{+}$Treg and $3 \mathrm{~A}^{-}$Treg cell numbers from $\mathrm{mLN}$ of juvenile Ifng ${ }^{-/-}(n=25)$ and Ifng ${ }^{+/+}(n=22)$ Bigenic mice shown. $\mathbf{i}$, $\mathbf{j}$ In vivo polarization of naïve polyclonal Thy $1.1^{+} \mathrm{T}_{\text {conv }}$ cells and $3 \mathrm{~A} 9^{+}$Thy $1.1^{+} \mathrm{T}_{\text {conv }}$ cells in newly weaned Ifng ${ }^{-/-}(n=10)$ and Ifng ${ }^{+/+}(n=8)$ Bigenic mice. Activation ( $\left.\% \mathrm{~T}_{\mathrm{EM}}\right)$ among Thy $1.1^{+} \mathrm{CD} 4^{+} \mathrm{T}_{\text {conv }}$ cells (i) and lineage commitment $\left(\mathrm{T}_{H} 17\right.$ or $\left.\mathrm{T}_{\mathrm{H}} 1\right)$ among $\mathrm{CD} 44^{+}$Thy $1.1^{+} \mathrm{CD} 4^{+} \mathrm{T}_{\text {conv }}$ cells (j) after sub-stratification into $3 \mathrm{~A}^{+}$and $3 \mathrm{~A} 9^{-}$clonotype groups. Paired $3 \mathrm{~A} 9^{-}$and $3 \mathrm{~A}^{+}$clonotype groups from the same mouse indicated with connecting line and significance for paired samples reflects the result of Wilcoxon matched-pairs signed rank test. ${ }^{1}$ In $5 \mathrm{~d}-5 \mathrm{~h}$, all Ifng ${ }^{-/}$Bigenic mice were symptomatic and $\sim 90 \%$ required euthanasia before the juvenile age

pathogenic to drive disease and instead reflect over-active homeostatic pathways compensating for decreased nTreg production. The central finding reported herein is that both IL-17A and IFNy contribute to the maintenance of this homeostatic state and ultimately facilitate the generation of antigen-specific tolerance to the ileal mucosa. Furthermore, we contend that disease progression results from the hypersensitivity of this overactive homeostatic process to normal immunomodulatory signals, such as IL-23, ${ }^{28,29}$ that limit mucosal tolerance to luminal bacteria (Fig. S6).

Treg cell abnormalities are reported for individuals with active $\mathrm{IBD}^{10}$ and defects in Treg cells cause colitis in mouse models. In both settings, Treg cell supplementation has shown clinical efficacy. ${ }^{30} \mathrm{~A}$ relative Treg deficiency permitted disease in our Bigenic model given that thymic nTreg production was low and supplementation with $\mathrm{nTreg}$ cells prevented all disease manifestations. Interestingly, nTreg infusion also prevented ileal-reactive Treg accumulation and supplementation with in vitro generated $3 \mathrm{~A} 9^{+}$iTreg cells alone also showed efficacy in preventing disease. Thus, while the Bigenic model may begin as a partial nTreg deficiency, some mice mold the repertoire of this numerically constrained Treg population to prevent disease progression. We did not address whether ileal-reactive Treg cells in Bigenic ${ }^{N S}$ mice are thymically derived or peripherally induced, however their reduced numbers following nTreg infusion suggests that they accumulate in response to a peripheral inflammatory process. Regardless of the ontogeny of these ileal-reactive Treg cells, our findings imply that Treg-mediated tolerance targeted at an antigen found only in the ileum is sufficient to prevent inflammatory disease in the colon.
Other enterocolitis models show highly penetrant disease where crypt hyperplasia is associated with morbidity. ${ }^{31,32}$ In contrast, we found that crypt hyperplasia was a characteristic of the ilea from Bigenic mice that lacked disease. Adaptive immune responses that judiciously target commensal organisms without dysregulating mucosal tolerance are a prominent feature of the healthy ileum. $^{18,22,33}$ Similarly, ilea of Bigenic mice can maintain mucosal tolerance while exhibiting this abnormal $\mathrm{T}_{H}$ 17-associated crypt hyperplasia. By targeting an ileal self-antigen with $\mathrm{CD} 4^{+} \mathrm{T}$ cells, we made ileal paracrine signaling more likely to impact $\mathrm{CD} 4^{+} \mathrm{T}$ cell responses that develop in Bigenic mice. Studies from Esplugues et al showed that intestinal trafficking can reduce the pathogenic activity of $\mathrm{CD}^{+}{ }^{+} \mathrm{T}$ cells. ${ }^{34}$ Thus, the accumulation of ileal-reactive Treg cells and declining incidence of colitic disease with age may reflect the systemic impact of ileal paracrine signaling. Findings from a related Bigenic system, where the mHEL target antigen was expressed in tissues other than the gastrointestinal (GI) mucosa, highlight the importance of specifically targeting the ileum. Shih et al. characterized a spontaneous wasting disease where relative nTreg deficiency dysregulated $3 \mathrm{~A}^{-} \mathrm{CD} 4^{+} \mathrm{T}$ cells and lead to colitis, however the authors identified very few mice without disease and did not report ileal involvement. ${ }^{35}$ This implies that the ileal microenvironment is essential for Bigenic ${ }^{N S}$ mice to compensate for the relative nTreg deficiency unmasked in 3A9 Bigenic systems.

The ilea of non-symptomatic Bigenic mice accumulated more $T_{H} 17$ cells than control mice suggesting that $T_{H} 17$ cells may also facilitate maintenance of homeostasis. Despite being identified by their association with IL-23-dependant autoimmune pathology, ${ }^{36}$ $\mathrm{T}_{\mathrm{H}} 17$ cells share a developmental axis with iTreg cells and can also manifest immunoregulatory phenotypes. ${ }^{37} \mathrm{~T}_{\mathrm{H}}$ 17-lineage mapping 

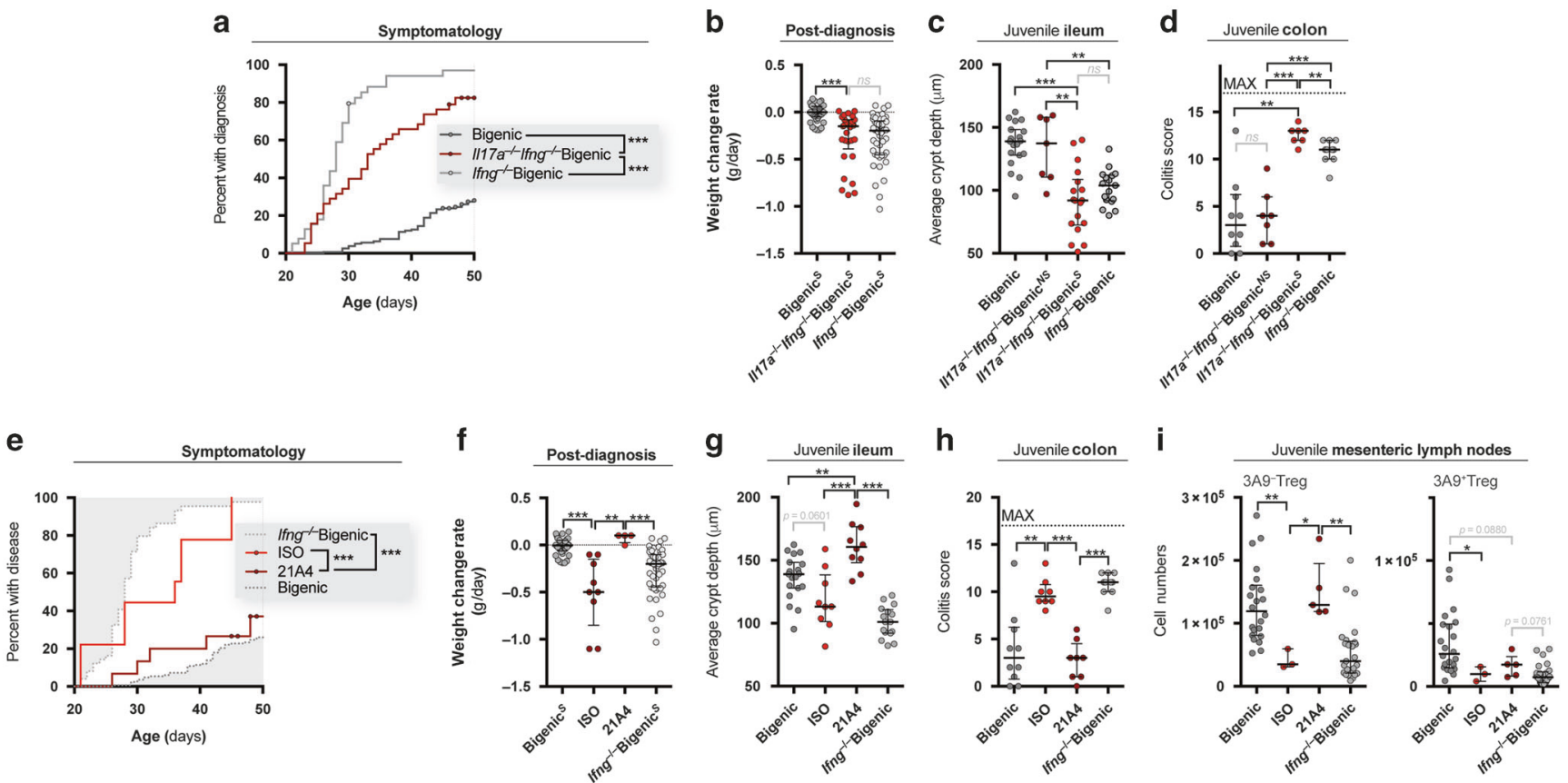

Fig. $6 \mathrm{IL}-17 \mathrm{~A}$ and IL-23 promote increased disease incidence in $/$ fng ${ }^{-/-}$Bigenic mice. a Prevalence of a wasting phenotype among $/ / 17 a^{-/-}$Ifng ${ }^{-1}$ -Bigenic $(n=39)$, Ifng ${ }^{-/-}$Bigenic $(n=38)$ and Bigenic $(n=159)$ mice during the juvenile period. b Weight change rate during the juvenile period following initial manifestation of the wasting phenotype for $1 / 17 a^{-/-}$Ifng ${ }^{-/-}$Bigenic $(n=29)$, Ifng $g^{-1-}$ Bigenic $(n=46)$ and Bigenic $(n=41)$

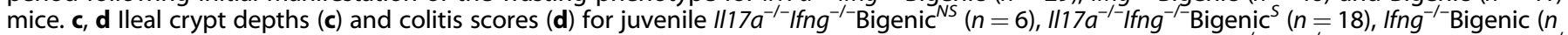

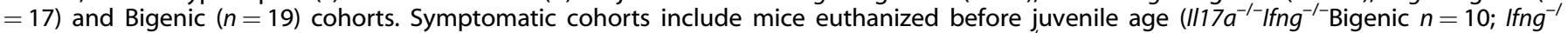
-Bigenic $n=15)$. e Prevalence of a wasting phenotype among IL-23R blockade treated Ifng ${ }^{-1-}$ Bigenic $(21 \mathrm{~A} 4 ; n=15)$, isotype control treated Ifng ${ }^{-/-}$Bigenic (ISO; $\left.n=9\right)$, Ifng ${ }^{-/-}$Bigenic $(n=50)$ and Bigenic $(n=157)$ mice during the juvenile period. f Weight change rate during the juvenile period following initial manifestation of the wasting phenotype for $21 \mathrm{~A} 4(n=4)$, ISO $(n=9)$, Ifng ${ }^{-1-}$ Bigenic $(n=50)$ and Bigenic $(n=$ 157) mice. $\mathbf{g}$, $\mathbf{h}$ lleal crypt depths (g) and colitis scores (h) for juvenile $21 \mathrm{~A} 4(n=10)$, ISO $(n=9)$, Ifng ${ }^{-/}$Bigenic $(n=16)$ and Bigenic $(n=19)$ mice. Symptomatic mouse cohorts include mice euthanized before juvenile endpoint (ISO $n=6 ;$ Ifng ${ }^{-1-}$ Bigenic $\left.n=15\right)$. i 3A9 ${ }^{+}$Treg and 3A9-Treg cell numbers from $\mathrm{mLN}$. Juvenile $21 \mathrm{~A} 4(n=10)$, ISO $(n=9)$, Ifng ${ }^{-1-}$ Bigenic $(n=25)$ and Bigenic $(n=22)$ mice shown. Most Ifng ${ }^{-1}$ -Bigenic mice required euthanasia before juvenile endpoint $(n=21)$

uncovered a prominent IL-23-independent role for $T_{H} 17$ cells in the induction of $\mathrm{T}$ cell-dependent IgA responses ${ }^{22}$ and conditional deletion of I117ra on the intestinal epithelium showed that $T_{H} 17$ cells also contribute to transcytosis of $\operatorname{lgA} .^{33}$ Both studies highlight important contributions of $T_{H} 17$ cells to homeostatic processes of intestinal tissues. Interestingly, $\mathrm{T}_{\mathrm{H}} 17$ cells produced in the setting of inflammatory disease that home to and are conditioned by the small intestine can acquire a regulatory phenotype. ${ }^{34}$ Our studies support this role for $\mathrm{T}_{\mathrm{H}} 17$ cells in homeostasis, as $1 / 17 a^{-/-}$Bigenic mice failed to accumulate ileal-reactive Treg cells in the $\mathrm{mLN}$ and were unable to prevent activation of naïve ileal-reactive $\mathrm{CD} 4^{+} \mathrm{T}$ cells. We recently reported a similar positive association between Treg and $T_{H} 17$ lineages as both were co-produced in the lymphopenic colitis model when mice were pre-treated with M2polarized macrophages. ${ }^{38}$ Though a number of studies indicate that IL-17A can limit the severity of bowel inflammation, 8,39 our data demonstrate that protective activity is in part due to the accumulation of mucosa-reactive Treg cells. Given more recent studies showing that IL-17A limits the growth of pro-inflammatory commensal microbes, ${ }^{33,40}$ IL-17A deficiency may result in dysregulated ileal-reactivity secondary to dysbiosis.

IL-17A does not contribute to pathogenesis in a consistent way across the various models of inflammatory disease. ${ }^{9,39,41}$ Furthermore, even when studying the same colitis model, genetic deletion of IL-17A and antibody blockade showed opposite effects on the outcome. ${ }^{9,39}$ These contradictory findings likely reflect the pleiotropic nature of IL-17A and thus suggest that its pathogenic potential is context-dependent. Opposing roles at different stages of disease have been described ${ }^{42}$ and this may explain why we did not see an increased incidence of disease in $1117 a^{-/-}$mice despite reduced ileal tolerance. Our model exhibits discrete stages and thus, it is possible that IL-17A promotes homeostasis yet also contributes to pathogenesis once homeostasis is disrupted. This interpretation is supported by $1117 a^{+1}$ ${ }^{+}$Ifng ${ }^{-1}$ Bigenic mice where the reduced ileal tolerance is associated with an IL-17A-dependent rise in the incidence of colitic disease. Thus, we expect that outcomes for individual Bigenic mice also depend on whether the juvenile mucosal environment favors the homeostatic development of IL-17Aproducing cells or pathogenic development, such as occurs in $\mathrm{T}_{\mathrm{H}} 17$ cells exposed to IL-23. ${ }^{43,44}$

Both $/ 17 a^{+/+}$and $/ 117 a^{-/-}$Bigenic $^{S}$ mice had increased $\mathrm{T}_{H} 1$ cells in the Gl lamina propria yet IFNY was essential for preventing highly penetrant and accelerated disease. IFN $\gamma$ directly inhibits $\mathrm{T}_{\mathrm{H}} 17$ development by reducing IL-23R expression ${ }^{36}$ and accordingly, Ifng ${ }^{-1}$ Bigenic mice also showed excessive $T_{H} 17$ production. IL-17A proved necessary for the high disease penetrance and progression was entirely dependent upon IL-23 signaling during the juvenile period. Thus, increased $T_{H} 17$ cell levels also appear to sensitize Bigenic mice to colitis.

Blocking IL-23 in Ifng ${ }^{-1-}$ Bigenic mice yielded many interesting findings with the first being the restored ileal crypt hyperplasia. The average crypt length was higher than that observed in any other Bigenic cohort, indicating a further exaggeration of the ileal homeostatic process seen in Bigenic ${ }^{N S}$ mice. We also observed increased Treg production following IL-23 blockade, consistent with the link between Treg production and ileal hyperplasia in Bigenic mice and with the inhibition of IL-23 in other models. ${ }^{29}$ 
a

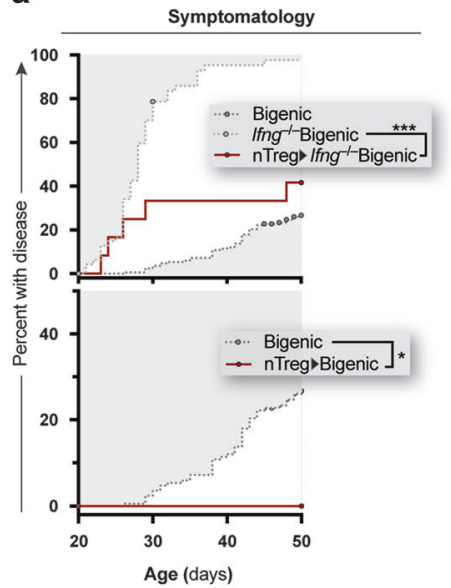

b

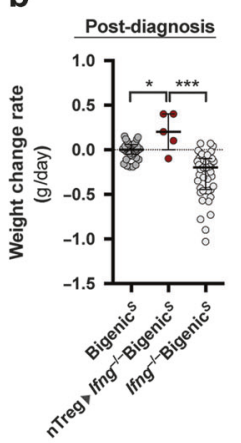

g

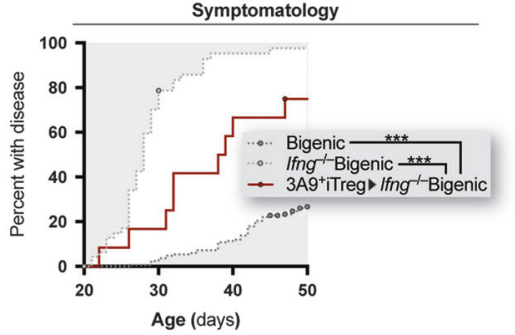
C

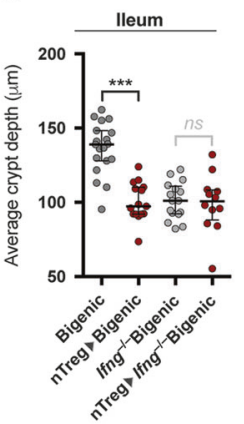

d
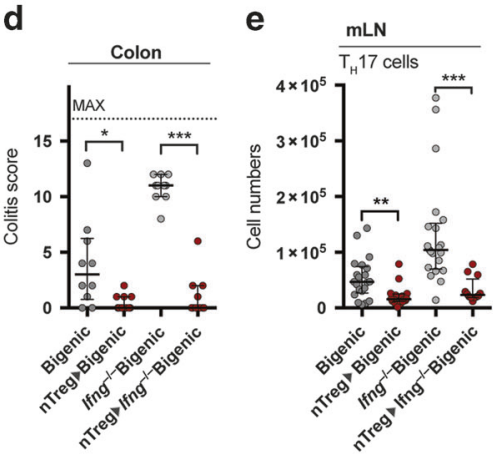

f

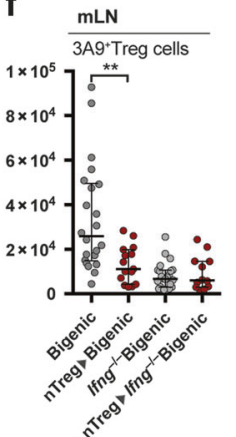

h

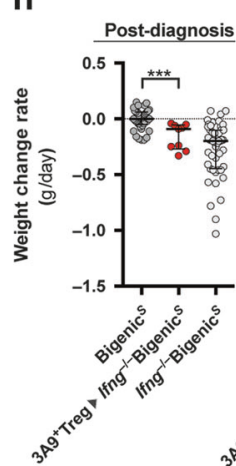

i

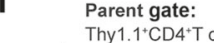

$100 \frac{\text { Thy } 1.1^{+} \mathrm{CD} 4^{+} \mathrm{T} \text { cells }}{1 R^{2}=0.661}$

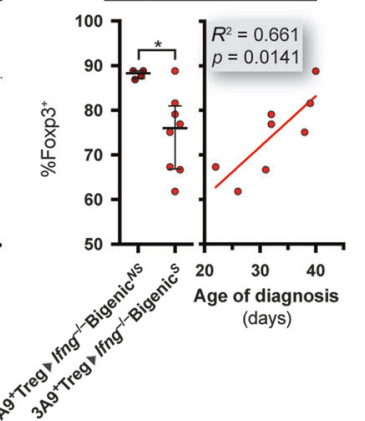

Fig. 7 nTreg treatment prevents ileal and colonic inflammation and $3 \mathrm{~A}^{+}{ }^{+}$iTreg treatment slows disease. a Prevalence of a wasting phenotype among nTreg-treated Bigenic $(n=18)$, nTreg-treated Ifng ${ }^{-/}$Bigenic $(n=12)$, Ifng ${ }^{-/-}$Bigenic $(n=47)$ and Bigenic $(n=167)$ mice during the juvenile period. b Weight change rate during the juvenile period following initial manifestation of the wasting phenotype for nTreg-treated Ifng ${ }^{-1-}$ Bigenic $(n=5)$, Ifng ${ }^{-1-}$ Bigenic $(n=46)$ and Bigenic $(n=41)$ mice. c, $\mathbf{d}^{\mathbf{1}}$ lleal crypt depths (c) and colitis scores (d) for juvenile $\mathrm{nTreg-}$ treated Bigenic $(n=19)$, nTreg-treated Ifng ${ }^{-1-}$ Bigenic $(n=12)$, Ifng ${ }^{-1-}$ Bigenic $(n=17)$ and Bigenic $(n=19)$ cohorts. e, $\mathbf{f}^{1}$ Numbers of $\mathrm{T}_{\mathrm{H}} 17(\mathbf{e})$ and $3 \mathrm{~A} 9^{+}$Treg (f) cells from mLN. Juvenile nTreg-treated Ifng ${ }^{-1-}$ Bigenic $(n=12)$, nTreg-treated Bigenic $(n=16)$, Ifng ${ }^{-1-}$ Bigenic $(n=21)$ and Bigenic $(n=21)$ mice shown. g Prevalence of a wasting phenotype among $3 A 9^{+}$iTreg-treated Ifng ${ }^{-1-}$ Bigenic $(n=12)$, Ifng ${ }^{-1-}$ Bigenic $(n=47)$ and Bigenic $(n=167)$ mice during the juvenile period. $\mathbf{h}$ Weight change rate during the juvenile period following initial manifestation of the wasting phenotype for $3 \mathrm{~A}^{+}$iTreg-treated Ifng ${ }^{-/-}$Bigenic $(n=9)$, Ifng ${ }^{-1-}$ Bigenic $(n=46)$ and Bigenic $(n=41)$ mice. i Foxp3 expression among transferred $3 A 9^{+}$iTreg cells at endpoint for treated Ifng ${ }^{-/-}$Bigenic $^{N S}(n=3)$ and Ifng ${ }^{-/-}$Bigenic $^{S}(n=9)$ mice (left). Expression from Ifng ${ }^{-/-}$Bigenic $^{S}$ mice $^{-}$ correlated to age of onset (right). ${ }^{1}$ In $7 \mathrm{c}-7 \mathrm{f}$, all Ifng ${ }^{-/-}$Bigenic mice were symptomatic and $\sim 90 \%$ required euthanasia before the juvenile age

Given the exaggerated production of $T_{H} 17$ cells in Ifng ${ }^{-/}$Bigenic mice subjected to IL-23R blockade, our findings suggest that nonpathogenic $T_{H} 17$ cells promote ileal crypt hyperplasia and regulatory $\mathrm{T}$ cell production. This raises the possibility for an unconventional treatment strategy whereby the stimulation of $\mathrm{T}_{\mathrm{H}} 17$ cell production in the setting of IL-23 blockade could restore durable mucosal tolerance through the mobilization of homeostasis-promoting $T_{H} 17$ cells and antigen-specific Treg cells.

\section{MATERIALS AAND METHODS}

Animals

HD5-mHEL mice were created similarly to previously reported CCSP-mHEL/Hb transgenic mice. ${ }^{45}$ A detailed description of the generation of this line all other lines used for breeding and adoptive transfer experiments can be found in the Supplemental Methods. The Animal Resource Committee at the Medical College of Wisconsin approved all animal experiments.

\section{Wasting phenotype diagnosis}

All progeny from experimental crosses were weighed every other day starting the day of weaning and ending at euthanasia. For days when an individual mouse was not weighed, we estimated the mouse's weight via a linear interpolation from the two nearest weight measurements. We applied three weight-based criteria to diagnose the presence of either poor growth or excessive weight loss symptomatology. These criteria are detailed in the Supplemental Methods.
Lymphocyte isolation

Lymphocytes were isolated from the entire thymus, spleen and $\mathrm{mLN}$. Lamina propria lymphocytes were isolated from the entire colon and distal $15 \mathrm{~cm}$ of the small intestine. Extraction procedures detailed further in Supplemental Methods.

Flow cytometry, cell sorting and adoptive transfer

Isolated lymphocytes were stained using both surface marker and intracellular cytokine staining panels as previously described. ${ }^{45} \mathrm{~A}$ four-laser custom LSRII was used to collect FACS data and FlowJo software was used for gating analysis. Primary and cultured cells were sorted using BD FACS Aria llu as previously descried and all adoptive transfers were i.p. injected. Further descriptions of these methods are provided in the Supplemental Methods section.

Histology

The entire colon and distal $4.5 \mathrm{~cm}$ of the small intestine were fixed in Zn Formalin. Post-fixation tissue processing, staining and slide scanning were performed by the Children's Research Institute Histology Core at MCW. Depths for $\sim 150$ crypts were measured for each scanned tissue section. Colitis was scored by a certified anatomic pathologist (MS) on basis of inflammation depth (0-2), epithelial cell reactive changes (0-3), mucosal architectural distortion (0-3) and inflammatory cell density in the lamina propria distention (0-3) without prior knowledge of the tissue genotype or disease history. Lymphoid aggregate foci and crypt aggregates were directly quantitated on scanned slides, reduced to 3-point scale and included in the aggregate score to give a max 
colitis score of 17. Chromogenic in situ hybridization was applied to visualize the location of mHEL-expressing cells. A detailed description of tissue staining, image analyses and colitis scoring is provided in the Supplemental Methods.

\section{Additional methods}

Detailed descriptions of the methods for serum studies, IL-23R blockade, and $3 \mathrm{~A}^{+}{ }^{+} \mathrm{i}$ Treg production can be found in the Supplemental Methods.

\section{Statistics}

Median and interquartile range shown on all graphs for univariate statistical analyses. All statistical tests were done on Prism 7. Outliers were removed from all examined datasets after Prism 7 Robust regression and Outlier removal analysis applying a ROUT coefficient (Q) of $1 \%$. The non-parametric Kruskal-Wallis test was applied for datasets with more than two comparison groups and if $p$ was less than 0.05 followed by Mann-Whitney test post-hoc to identify which groups account for significant findings. Differences between the prevalence vs. age curves were detected using the Mantel-Cox Log-rank test. Significance thresholds were marked with the Prism 7 symbol convention: * for $0.05>p>0.01,{ }^{* *}$ for $0.01>p>0.001,{ }^{* * *}$ for $0.001>p$.

\section{ACKNOWLEDGEMENTS}

We thank Paul Allen for the gift of 3A9 mice and Daniel Cua for the gift of the 21A4 (alL23R) antibody. We also thank Dipica Haribhai, Erica Schmitt, Lily Allison, and Lauren Drobyski for technical assistance. This work was supported by grants from the following sources: R01 Al085090 (CBW), F32Al092977 (CGM), a Senior Research Award from the Crohn's and Colitis Foundation (CBW), the D.B. and Marjorie Reinhart Family Foundation Endowed Chair in Rheumatology (CBW), and from the Children's Hospital of Wisconsin (CBW).

\section{AUTHOR CONTRIBUTIONS}

J.C.J. designed and performed experiments, developed the system for scoring disease based on weight, designed figures and wrote the manuscript. C.G.M. generated the transgenic HD5-mHEL line. C.G.M., C.L.D., J.Z,. S.S., and S.N.K. performed experiments and edited the manuscript. Y.I. provided a critical reagent and MS developed the scoring system and scored all histopathology. W.R.D. and N.H.S. designed experiments, provided critical reagents, and edited the manuscript. C.B.W. developed the overall concept, supervised the study, designed experiments, and wrote the manuscript.

\section{ADDITIONAL INFORMATION}

The online version of this article (https://doi.org/10.1038/s41385-018-0023-6) contains supplementary material, which is available to authorized users.

\section{REFERENCES}

1. Khor, B., Gardet, A. \& Xavier, R. J. Genetics and pathogenesis of inflammatory bowel disease. Nature 474, 307-317 (2011).

2. Sandborn, W. J. et al. Adalimumab for maintenance treatment of Crohn's disease: results of the CLASSIC II trial. Gut 56, 1232-1239 (2007).

3. Billioud, V., Sandborn, W. J. \& Peyrin-Biroulet, L. Loss of response and need for adalimumab dose intensification in Crohn's disease: a systematic review. Am. J. Gastroenterol. 106, 674-684 (2011).

4. Sandborn, W. J. et al. A randomized trial of Ustekinumab, a human interleukin-12/ 23 monoclonal antibody, in patients with moderate-to-severe Crohn's disease. Gastroenterology 135, 1130-1141 (2008).

5. Hueber, W. et al. Secukinumab, a human anti-IL-17A monoclonal antibody, for moderate to severe Crohn's disease: unexpected results of a randomised, doubleblind placebo-controlled trial. Gut 61, 1693-1700 (2012).

6. Reinisch, W. et al. Fontolizumab in moderate to severe Crohn's disease: a phase 2, randomized, double-blind, placebo-controlled, multiple-dose study. Inflamm. Bowel Dis. 16, 233-242 (2010).
7. Powrie, F. et al. Inhibition of Th1 responses prevents inflammatory bowel disease in scid mice reconstituted with CD45RBhi CD4 + T cells. Immunity 1, 553-562 (1994).

8. O'Connor, W. Jr. et al. A protective function for interleukin 17A in T cell-mediated intestinal inflammation. Nat. Immunol. 10, 603-609 (2009).

9. Ito, R. et al. Involvement of IL-17A in the pathogenesis of DSS-induced colitis in mice. Biochem. Biophys. Res. Commun. 377, 12-16 (2008).

10. Maul, J. et al. Peripheral and intestinal regulatory CD4 $+\mathrm{CD} 25$ (high) $\mathrm{T}$ cells in inflammatory bowel disease. Gastroenterology 128, 1868-1878 (2005).

11. Mowat, A. M. \& Agace, W. W. Regional specialization within the intestinal immune system. Nat. Rev. Immunol. 14, 667-685 (2014).

12. Johansson, M. E. et al. The inner of the two Muc2 mucin-dependent mucus layers in colon is devoid of bacteria. Proc. Natl Acad. Sci. USA 105, 15064-15069 (2008).

13. Ermund, A., Schutte, A., Johansson, M. E., Gustafsson, J. K. \& Hansson, G. C. Studies of mucus in mouse stomach, small intestine, and colon. I. Gastrointestinal mucus layers have different properties depending on location as well as over the Peyer's patches. Am. J. Physiol. Gastrointest. Liver Physiol. 305, G341-347 (2013).

14. Meyer-Hoffert, $\mathrm{U}$. et al. Secreted enteric antimicrobial activity localises to the mucus surface layer. Gut 57, 764-771 (2008).

15. Vaishnava, S. et al. The antibacterial lectin Reglllgamma promotes the spatial segregation of microbiota and host in the intestine. Science 334, 255-258 (2011).

16. Bevins, C. L. \& Salzman, N. H. Paneth cells, antimicrobial peptides and maintenance of intestinal homeostasis. Nat. Rev. Microbiol. 9, 356-368 (2011).

17. Kolls, J. K., McCray, P. B. Jr. \& Chan, Y. R. Cytokine-mediated regulation of antimicrobial proteins. Nat. Rev. Immunol. 8, 829-835 (2008).

18. Bunker, J. J. et al. Innate and adaptive humoral responses coat distinct commensal bacteria with immunoglobulin A. Immunity 43, 541-553 (2015).

19. Macpherson, A. J., Hunziker, L., McCoy, K. \& Lamarre, A. IgA responses in the intestinal mucosa against pathogenic and non-pathogenic microorganisms. Microbes Infect. / Inst. Pasteur 3, 1021-1035 (2001).

20. Tsuji, M. et al. Preferential generation of follicular B helper T cells from Foxp3 + T cells in gut Peyer's patches. Science 323, 1488-1492 (2009).

21. Wang, S. et al. MyD88 adaptor-dependent microbial sensing by regulatory T cells promotes mucosal tolerance and enforces commensalism. Immunity 43, 289-303 (2015).

22. Hirota, K. et al. Plasticity of Th17 cells in Peyer's patches is responsible for the induction of T cell-dependent IgA responses. Nat. Immunol. 14, 372-379 (2013).

23. Kelly, M. N. et al. Interleukin-17/interleukin-17 receptor-mediated signaling is important for generation of an optimal polymorphonuclear response against Toxoplasma gondii infection. Infect. Immun. 73, 617-621 (2005).

24. Becker, C. et al. Constitutive p40 promoter activation and IL-23 production in the terminal ileum mediated by dendritic cells. J. Clin. Investig. 112, 693-706 (2003).

25. McGeachy, M. J. \& Cua, D. IL-23 is vital for effector Th17 cell function in vivo. Cytokine 39, 26-27 (2007).

26. McGeachy, M. J. et al. The interleukin 23 receptor is essential for the terminal differentiation of interleukin 17-producing effector $\mathrm{T}$ helper cells in vivo. Nat. Immunol. 10, 314-324 (2009).

27. Schmitt, E. G. et al. IL-10 produced by induced regulatory T cells (iTregs) controls colitis and pathogenic ex-iTregs during immunotherapy. J. Immunol. 189, 5638-5648 (2012).

28. Mangan, P. R. et al. Transforming growth factor-beta induces development of the $\mathrm{T}(\mathrm{H}) 17$ lineage. Nature 441, 231-234 (2006).

29. Izcue, A. et al. Interleukin-23 restrains regulatory $T$ cell activity to drive $T$ celldependent colitis. Immunity 28, 559-570 (2008).

30. Desreumaux, P. et al. Safety and efficacy of antigen-specific regulatory T-cell therapy for patients with refractory Crohn's disease. Gastroenterology 143, 1207-1217 (2012). e1201-1202.

31. Matsumoto, S. et al. Inflammatory bowel disease-like enteritis and caecitis in a senescence accelerated mouse P1/Yit strain. Gut 43, 71-78 (1998).

32. Kontoyiannis, D., Pasparakis, M., Pizarro, T. T., Cominelli, F. \& Kollias, G. Impaired on/off regulation of TNF biosynthesis in mice lacking TNF AU-rich elements: implications for joint and gut-associated immunopathologies. Immunity 10, 387-398 (1999).

33. Kumar, P. et al. Intestinal interleukin-17 receptor signaling mediates reciprocal control of the gut microbiota and autoimmune inflammation. Immunity 44, 659-671 (2016).

34. Esplugues, E. et al. Control of TH17 cells occurs in the small intestine. Nature 475, 514-518 (2011).

35. Shih, F. F., Mandik-Nayak, L., Wipke, B. T. \& Allen, P. M. Massive thymic deletion results in systemic autoimmunity through elimination of $\mathrm{CD} 4+\mathrm{CD} 25+\mathrm{T}$ regulatory cells. J. Exp. Med. 199, 323-335 (2004). 
A model of TH17-associated ileal hyperplasia...

JC Jeschke et al.

36. Harrington, L. E. et al. Interleukin 17-producing CD4+ effector T cells develop via a lineage distinct from the T helper type 1 and 2 lineages. Nat. Immunol. 6 , 1123-1132 (2005).

37. McGeachy, M. J. et al. TGF-beta and IL- 6 drive the production of IL-17 and IL-10 by $\mathrm{T}$ cells and restrain $\mathrm{T}(\mathrm{H})-17$ cell-mediated pathology. Nat. Immunol. 8 , 1390-1397 (2007).

38. Haribhai, D. et al. Alternatively activated macrophages boost induced regulatory $\mathrm{T}$ and Th17 cell responses during immunotherapy for colitis. J. Immunol. 196, 3305-3317 (2016).

39. Ogawa, A., Andoh, A., Araki, Y., Bamba, T. \& Fujiyama, Y. Neutralization of interleukin-17 aggravates dextran sulfate sodium-induced colitis in mice. Clin. Immunol. 110, 55-62 (2004).

40. Varelias, A. et al. Acute graft-versus-host disease is regulated by an IL-17-sensitive microbiome. Blood 129, 2172-2185 (2017).
41. Leppkes, M. et al. RORgamma-expressing Th17 cells induce murine chronic intestinal inflammation via redundant effects of IL-17A and IL-17F. Gastroenterology 136, 257-267 (2009).

42. Odobasic, D. et al. Interleukin-17A promotes early but attenuates established disease in crescentic glomerulonephritis in mice. Am. J. Pathol. 179, 1188-1198 (2011).

43. Yen, D. et al. IL-23 is essential for T cell-mediated colitis and promotes inflammation via IL-17 and IL-6. J. Clin. Investig. 116, 1310-1316 (2006).

44. Lee, Y. et al. Induction and molecular signature of pathogenic TH17 cells. Nat. Immunol. 13, 991-999 (2012).

45. Schmitt, E. G. et al. Chronic follicular bronchiolitis requires antigen-specific regulatory $\mathrm{T}$ cell control to prevent fatal disease progression. J. Immunol. 191 5460-5476 (2013). 